University of Wollongong

Research Online

Australian Institute for Innovative Materials -

Papers

Australian Institute for Innovative Materials

$1-1-2017$

\title{
Phosphorus-Based Materials as the Anode for Sodium-Ion Batteries
}

Fuhua Yang

University of Wollongong, fy896@uowmail.edu.au

Hong Gao

University of Wollongong, hg173@uowmail.edu.au

Jun Chen

University of Wollongong, junc@uow.edu.au

Zaiping Guo

University of Wollongong, zguo@uow.edu.au

Follow this and additional works at: https://ro.uow.edu.au/aiimpapers

Part of the Engineering Commons, and the Physical Sciences and Mathematics Commons

Research Online is the open access institutional repository for the University of Wollongong. For further information contact the UOW Library: research-pubs@uow.edu.au 


\section{Phosphorus-Based Materials as the Anode for Sodium-Ion Batteries}

\section{Keywords}

phosphorus-based, anode, batteries, materials, sodium-ion

Disciplines

Engineering | Physical Sciences and Mathematics

\section{Publication Details}

Yang, F., Gao, H., Chen, J. \& Guo, Z. (2017). Phosphorus-Based Materials as the Anode for Sodium-Ion Batteries. Small Methods, 1 (11), 1700216-1-1700216-14. 


\title{
Phosphorus-Based Materials as the Anode for Sodium-Ion Batteries
}

\author{
Fuhua Yang, Hong Gao, Jun Chen, * and Zaiping Guo*
}

As a promising alternative to lithium-ion batteries, sodium-ion batteries (SIBs) have recently attracted considerable attention. Enormous effort has been devoted to investigations on the development of suitable active materials in order to improve the energy density of SIBs and give them significant cycling stability. Among the reported anode materials, phosphorus-based materials have been recognized as a major group of promising anode materials, due to the high theoretical capacity of $\mathrm{P}\left(2596 \mathrm{~mA} \mathrm{~h}^{-1}\right)$ and the abundance of $\mathrm{P}$ rock resources. Here, the current progress on P-based anode materials is summarized, including elemental $\mathbf{P}$ (red/black phosphorus) and metal phosphides (Co-P, Cu-P, $\mathrm{Fe}-\mathrm{P}, \mathrm{Ni}-\mathrm{P}, \mathrm{Se}-\mathrm{P}, \mathrm{Sn}-\mathrm{P}, \mathrm{Ge}-\mathrm{P})$, and challenges and perspectives are highlighted in order to provide guidance for future research in related areas. Typical articles are also selected as specific examples, elaborating the advances in materials preparation techniques/approaches and in the structural design of P-based materials.

\section{Introduction}

Despite the huge success of lithium-ion batteries (LIBs), the limited nature of lithium resources has led to a focus on alternative rechargeable battery technologies, such as sodium-ion batteries (SIBs), ${ }^{[1]}$ potassium-ion batteries, ${ }^{[2]}$ and aluminum-ion batteries. ${ }^{[3]}$ SIBs in particular have gained a substantial amount of attention, ${ }^{[4,5]}$ due to the abundant sodium resources in the Earth's crust and the comparable electrochemical performance to LIBs. Nevertheless, the relatively large size of the $\mathrm{Na}^{+}$ion (the radius of the $\mathrm{Na}^{+}$ion is

F. Yang, H. Gao, Prof. Z. Guo

Institute for Superconducting and Electronic Materials

School of Mechanical

Materials and Mechatronics Engineering

University of Wollongong

Wollongong, NSW 2522, Australia

E-mail: zguo@uow.edu.au

Prof. J. Chen

ARC Centre of Excellence for Electromaterials Science

Intelligent Polymer Research Institute

Australian Institute of Innovative Materials

University of Wollongong

North Wollongong, NSW 2522, Australia

E-mail: junc@uow.edu.au

The ORCID identification number(s) for the author(s) of this article can be found under https://doi.org/10.1002/smtd.201700216.

DOI: $10.1002 /$ smtd.201700216
$55 \%$ larger than that of $\mathrm{Li}^{+}$) means that conventional LIB electrode materials are not suitable for SIBs. Therefore, developing suitable electrode materials with high theoretical capacity has become one of the key challenges to effectively improving SIB performance, in terms of both energy density and power density. ${ }^{[6,7]}$ This is because the fundamental electrochemistry of rechargeable battery devices is mainly determined by the selected active electrode materials.

A vast number of studies have been conducted on cathode materials, but the research investigation of promising anode materials is still in a relatively early stage. ${ }^{[5,8]}$ In the early period, many traditional anode materials with the intercalation mechanism were reported, such as carbonaceous materials and metal oxides, ${ }^{[7,9]}$ which showed excellent cycling stability. Their limited theoretical capacities, however, are restricting their further application in SIBs. In order to achieve higher energy density, high-capacity anode materials need to be explored. Among the previously reported highcapacity anode materials (e.g., metals, phosphorus, phosphides, and sulfides), phosphorus-based materials, including elemental $\mathrm{P}$ and metal phosphides, are regarded as one of the most promising anode material groups for enhancing the energy density of SIBs. ${ }^{[7,10]}$ Phosphorus, in particular, has the highest theoretical capacity of $2596 \mathrm{~mA} \mathrm{~h} \mathrm{~g}$, based on its sodiation mechanism $\left(\mathrm{P}+3 \mathrm{Na}^{+}+3 \mathrm{e}^{-} \rightarrow \mathrm{Na}_{3} \mathrm{P}\right)$, in which three electrons are required to form $\mathrm{Na}_{3} \mathrm{P}$. Combining $\mathrm{P}$ with metals to form metal phosphides, such as $\mathrm{NiP}_{3}$, FeP, CoP, and $\mathrm{Sn}-\mathrm{P}$, can also improve the electrical conductivity and prevent the pulverization issue to some extent. In recent years, efforts have been made mainly on three aspects (surface modification, dimension reduction, and structure optimization) to improve the sodium-storage performance of P-based materials. Previous studies have demonstrated that surface modification can improve the electrochemical properties of P-based materials, ${ }^{[11,12]}$ while dimension reduction and structural optimization facilitate electron $/ \mathrm{Na}^{+}$transportation and alleviate the volume expansion (Figure 1). ${ }^{[13-16]}$

Here, we focus on the recent progress regarding P-based anode materials for SIBs, especially the structural design and the fabrication process. In addition, we also summarize the various strategies and processing protocols used to enhance the electrochemical performance of the active materials. 


\section{Phosphorus}

Phosphorus, which is located in the 5A group of the periodic table, has three main allotropes: white, red, and black. Among them, white $\mathrm{P}$ (WP) is a chemically reactive and toxic material. ${ }^{[22]}$ While red $\mathrm{P}(\mathrm{RP})$ and black $\mathrm{P}(\mathrm{BP})$ are relatively stable, and both of them can effectively accommodate sodium ions, ${ }^{[23,24]}$ the large volume expansion during the sodiation process results in fast capacity fading of both RP and BP. Furthermore, RP is electrically insulating, while $\mathrm{BP}$ is hard to synthesize. Recently, considerable efforts have been made to solve and overcome these problems.

\subsection{Red Phosphorus}

As a material for SIB anodes, the advantages of RP are obvious: ${ }^{[7,25-27]}$ i) a high theoretical capacity of $2596 \mathrm{~mA} \mathrm{~h} \mathrm{~g}^{-1}$ (in view of the reaction of $\mathrm{P}$ with three $\mathrm{Na}^{+}$to form $\mathrm{Na}_{3} \mathrm{P}$ ); ii) relatively low redox potential $\left(0.4 \mathrm{~V}\right.$ vs Na/Na $\left.{ }^{+}\right)$, which could result in high energy density, whereas the redox potential of RP in LIBs is $\approx 0.8 \mathrm{~V}$ versus $\mathrm{Li} / \mathrm{Li}^{+}$; and iii) the abundance of $\mathrm{P}$ rock resources makes RP favorable for industrialization. Despite the above merits, the poor conductivity $\left(\approx 1 \times 10^{-14} \mathrm{~S} \mathrm{~cm}^{-1}\right)$ and the large volume changes $(\approx 400 \%)$ of the pure RP lead to fast capacity fading and low Coulombic efficiency, thus impeding the application of RP in SIBs. ${ }^{[23,28-30]}$ To overcome these scientific and technical issues, researchers have designed RP-based composites with various frameworks to improve its conductivity and cycling stability, and the design considerations mainly arise from the following aspects: i) the need to introduce various conductive matrices in order to improve the electronic conductivity and suppress the volume expansion of RP during electrochemical processes; and ii) the need to minimize the RP particle size and even form RP-carbon bonds to control the $\mathrm{P}$ volume changes and shorten the ion and electron diffusion lengths during cycling. ${ }^{[31,32]}$

\subsubsection{Ball/Hand-Milling Processes to Obtain RP/C Composites}

Ball milling is one of the main approaches to preparing $\mathrm{RP} / \mathrm{C}$ composites, due to its advantageous processing properties, such as being facile, simple, and easily scaled up. ${ }^{[12,33,34]}$ Amorphous RP/C composites produced via the ball-milling method as an anode for SIBs were reported by $\mathrm{Oh}$ and co-workers ${ }^{[12]}$ and Yang and co-workers, ${ }^{[34]}$ simultaneously and separately in 2013. As shown in the scanning and transmission electron microscopy (SEM and TEM) images (Figure 2a,b) from Oh's work, ${ }^{[12]}$ the particle size of the final product is uneven, ranging from hundreds of nanometers to several micrometers. This composite delivered a reversible capacity of $1890 \mathrm{~mA} \mathrm{~h} \mathrm{~g}^{-1}$ at $143 \mathrm{~mA} \mathrm{~g}^{-1}$, and the capacity fading was less than $7 \%$ over 30 cycles (Figure 2c,d). Even though the performance was much better than that of the pure RP electrode, the low current density and limited number of cycles still leave room for improvement.

Similarly, an RP/graphene nanosheet composite was synthesized by the ball-milling method ${ }^{[35]}$ (Figure 2e). In this

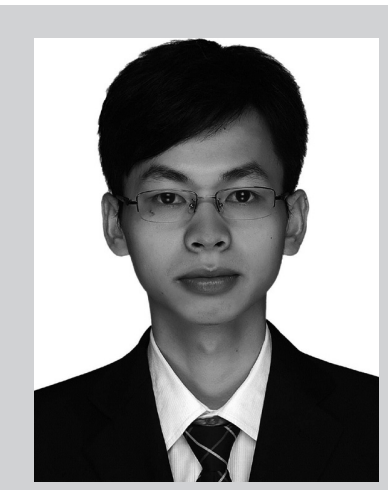

Fuhua Yang received his Bachelor's and Master's degrees from Central South University, China, in 2013 and 2016 , respectively. $\mathrm{He}$ is now a Ph.D. candidate at the University of Wollongong, Australia. His research interests are focused on anode materials for sodium-ion and potassium-ion batteries.

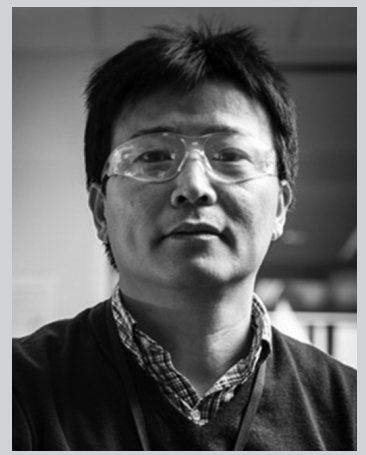

Jun Chen is currently appointed as a Full Professor at the Australian Institute of Innovative Materials (AIIM), University of Wollongong (UOW). He completed his Ph.D. degree at the School of Chemistry, UOW, Australia, in 2003. He is a Chief Investigator of The ARC Centre of Excellence for Electromaterials Science (ACES). His current research interests include synthetic energy systems, electro/biointerfaces, nano-/micromaterials, and device design and fabrication.

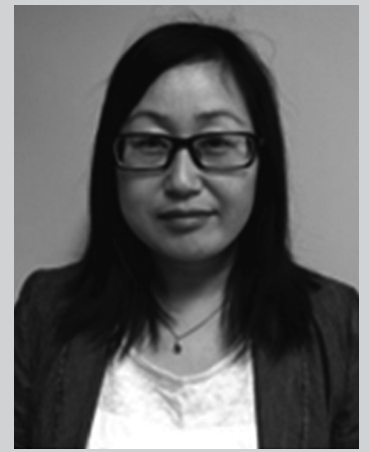

Zaiping Guo received her Ph.D. in materials engineering from the University of Wollongong in December 2003. After her Australian Postdoctoral (APD) Fellowship at the Institute for Superconducting and Electronic Materials, she joined the Faculty of Engineering and Information Sciences, University of Wollongong as a lecturer in 2008. She was promoted to professor in 2012 and then to senior professor in 2013. Her current research interests are focused on the design and application of nanomaterials for energy storage and conversion, including rechargeable batteries, hydrogen storage, and fuel cells.

experiment, it was found that the existence of $\mathrm{P}-\mathrm{O}-\mathrm{C}$ bonds was a critical factor in maintaining contact between the RP and the graphene nanosheets. As a result, an outstanding cycling stability of $1700 \mathrm{~mA} \mathrm{~h} \mathrm{~g}{ }^{-1}$ for over 60 cycles was obtained (Figure 2f). Despite some advances, the ball-milling strategy still presents some issues: i) ball milling is a high-energyconsuming and structure-destroying process; and ii) the relatively large particle size of RP and the incomplete coverage by 


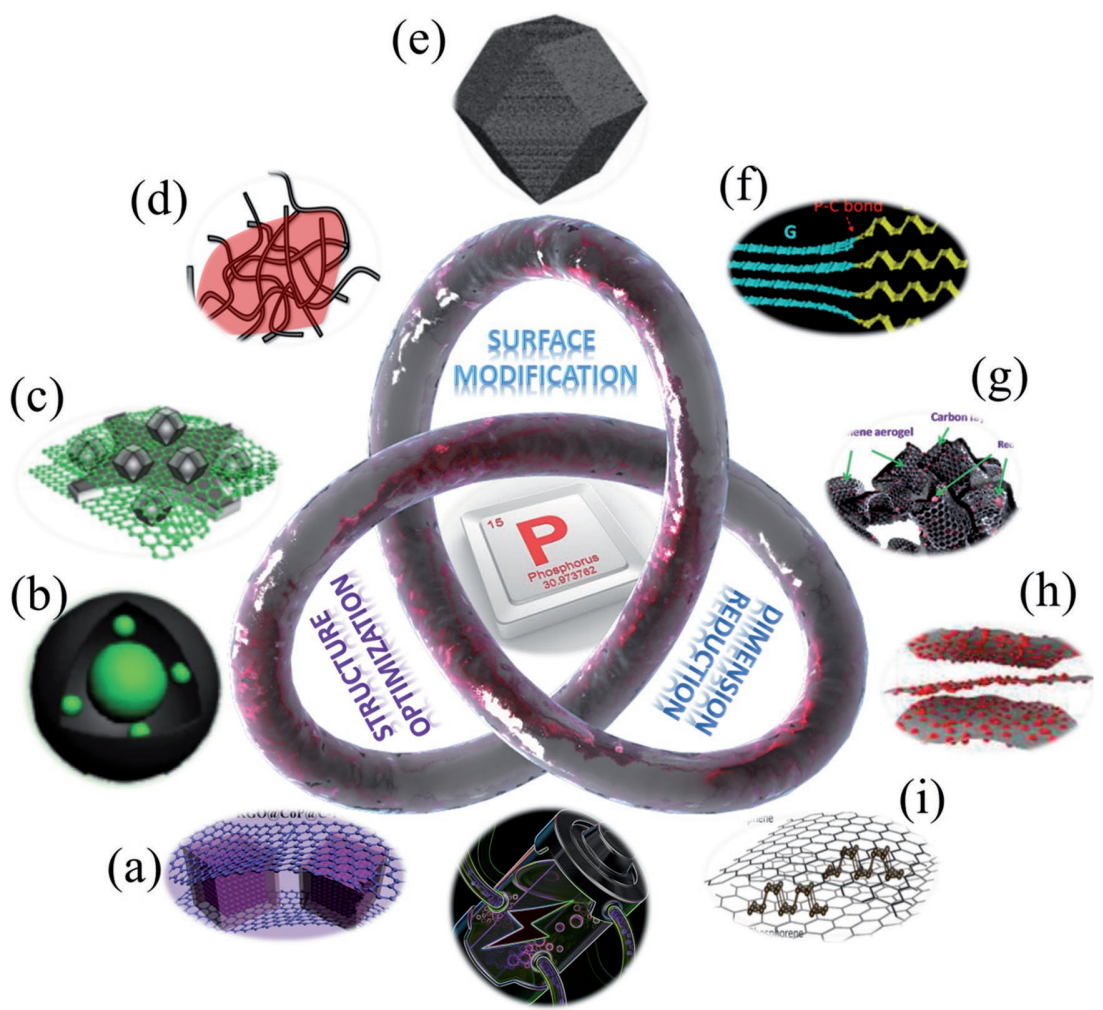

\section{P-based Materials as Anode for Sodium-ion Batteries}

Figure 1. Schematic illustration of P-based materials as anode for sodium-ion batteries. a) Reproduced with permission. ${ }^{[17]}$ Copyright 2017, Elsevier. b) Reproduced with permission. ${ }^{[14]}$ Copyright 2015, Royal Society of Chemistry. c) Reproduced with permission. ${ }^{[18]}$ Copyright 2017, Elsevier. d) Reproduced with permission. ${ }^{[19]}$ Copyright 2015. American Chemical Society. e) Reproduced with permission. ${ }^{[16]}$ Copyright 2017 , Wiley- $\mathrm{VCH}$. f) Reproduced with permission. ${ }^{[11]}$ Copyright 2014, American Chemical Society. g) Reproduced with permission. ${ }^{[20]}$ Copyright 2016, Wiley-VCH. h) Reproduced with permission. [13] Copyright 2017, American Chemical Society. i) Reproduced with permission. ${ }^{[21]}$ Copyright 2015, Nature Publishing Group.

the conductive matrix would hinder future improvement of $\mathrm{RP} /$ carbon composites for SIBs.

A simple hand-milling method has also been employed to fabricate an RP/multiwalled carbon nanotube (MWCNT) composite. ${ }^{[28]}$ Compared with ball-milled composites, the simple hand mixing of RP/MWCNTs with microsized RP and uneven coverage of the MWCNTs resulted in an even faster capacity fading (capacity retention of $76.6 \%$ after just ten cycles).

\subsubsection{Vaporization/Adsorption Technique to Synthesize $\mathrm{RP} / \mathrm{C}$ Composites}

The vaporization/adsorption strategy is an alternative approach to preparing $\mathrm{RP} /$ carbon composites. ${ }^{[36]}$ Compared to the ballmilling method, the vaporization/adsorption strategy is a nondestructive process, ensuring that the RP is uniformly dispersed in the integrated carbon matrix. Normally, the mechanism for this technique is: ${ }^{[29,36,19,37]}$ i) the RP is heated to form $\mathrm{P}_{4}$ vapor at a temperature higher than the RP sublimation temperature; ii) the sublimation is driven by pressure differences, and the $\mathrm{P}_{4}$ vapor diffuses into the empty spaces of the carbon framework/matrix, where it is then adsorbed and deposited on the internal surfaces; and iii) after condensation, the $\mathrm{P}_{4}$ turns back into $\mathrm{RP}$ to yield the nanostructured $\mathrm{RP} /$ carbon composite.

Wang and co-workers ${ }^{[19]}$ reported a modified vaporization-condensation method to prepare RP/single-walled carbon nanotube (SWCNT) composites for SIBs. The synthesis was conducted at a higher temperature $\left(600{ }^{\circ} \mathrm{C}\right)$ and under vacuum conditions, which could create a strong driving force to cause easy adsorption of the $\mathrm{P}_{4}$ vapor into the SWCNTs and is favorable for a uniform dispersion of RP in the SWCNTs. The RP/ SWCNT composite exhibited a capacity of $\approx 700 \mathrm{~mA} \mathrm{~h} \mathrm{~g}^{-1}$ under $50 \mathrm{~mA} \mathrm{~g}^{-1}$ (based on the composite weight) and a high capacity retention of $80 \%$ after 2000 cycles (Figure 3a,b).

Subsequently, an amorphous RP@Ndoped graphene $(\mathrm{GN})^{[38]}$ was synthesized by a phase-transformation route, through which amorphous RP was embedded in the N-doped graphene paper to form a "bread-and-butter"like structure. The RP@GN composite could demonstrate stable cycling performance and outstanding rate capacity of $809 \mathrm{~mA} \mathrm{~h} \mathrm{~g}^{-1}$ under $1500 \mathrm{~mA} \mathrm{~g}^{-1}$ (Figure 3c,d). Although greatly enhanced performance was achieved, the uncontrollability of the RP distribution in the traditional vaporization/adsorption technique would affect the loading level and the carbon coverage of the RP..$^{[13,16]}$

In order to optimize the loading level and solve the carbon coverage problems for the RP/C composite, our group reported an advanced vapor-redistribution strategy using an in situ localized redistribution approach to fabricate a C@RP/graphene aerogel (GA) composite. ${ }^{[20]}$ Graphene aerogel has abundant active sites and an interconnected 3D porous framework, which would provide excellent accommodation for RP particles and a superior 3D conductive network. In the fabrication process, the RP is first incorporated into the GA, and then polypyrrole is utilized to further encapsulate the RP throughout the whole framework, which is followed by vapor redistribution of the localized RP (Figure 4a). Unlike the traditional vaporization/adsorption strategy, where RP vapor is adsorbed from the outside, this technique vapor-redistributes the localized RP throughout the whole structure. This technique can control the distribution paths of the RP vapor and improve the loading level of RP. The C@RP/GA features nanosized RP homogeneously distributed in and mostly covered by the designed 3D porous structure (Figure 4b,c). The C@RP/ GA electrode exhibited a specific capacity of $1867 \mathrm{~mA} \mathrm{~h} \mathrm{~g}^{-1}$ at $260 \mathrm{~mA} \mathrm{~h} \mathrm{~g}^{-1}$ after 100 cycles and excellent rate performance (Figure 4d,e).

Compared to the ball-milling method, the vaporization/ adsorption technique is a mild process that does not destroy the structure, although the phase-transformation process will 

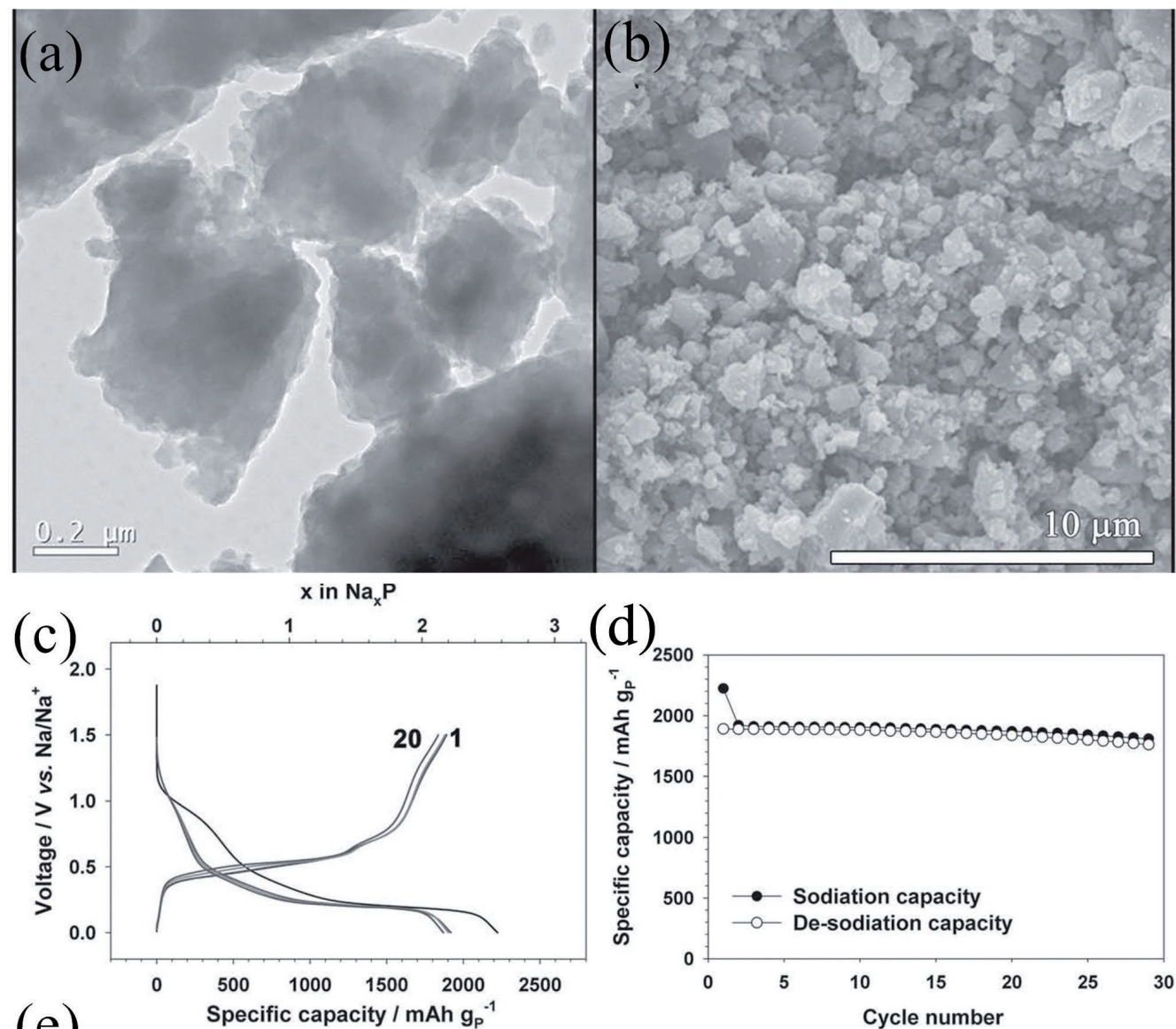

(d)
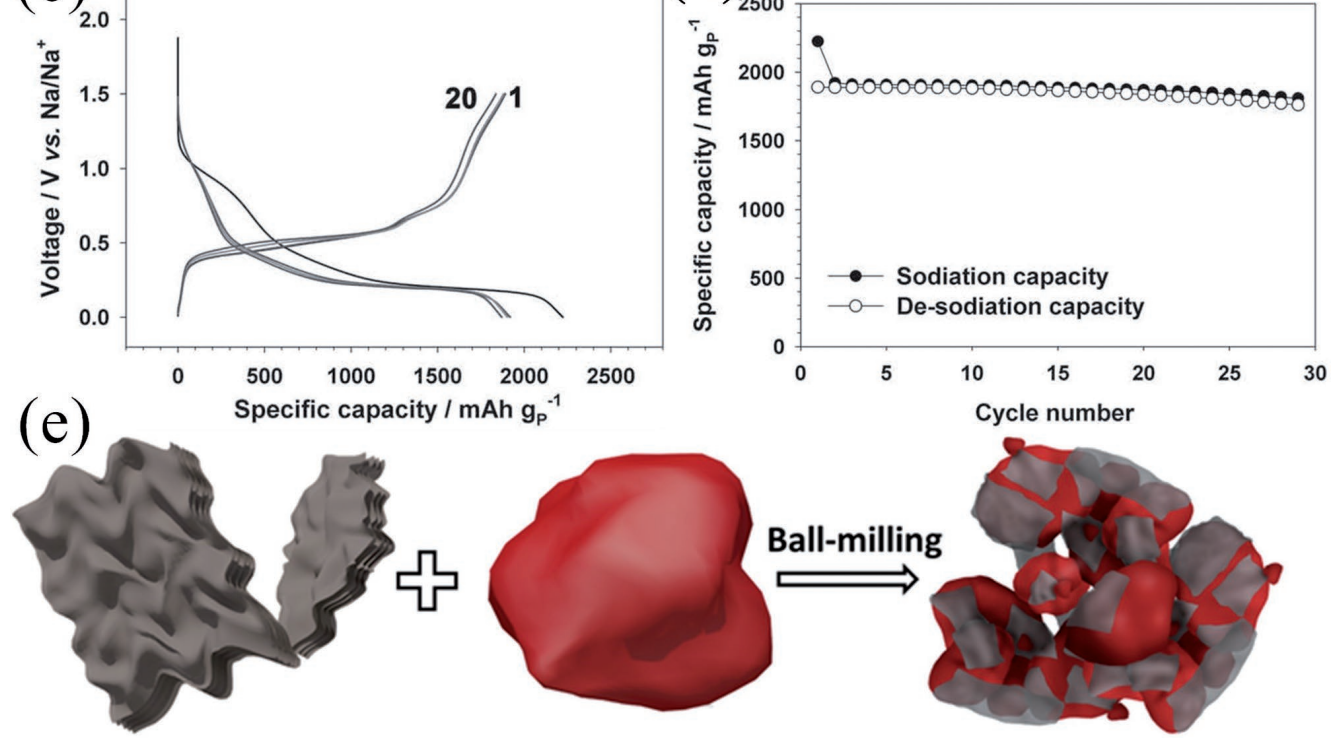

Graphene Stacks

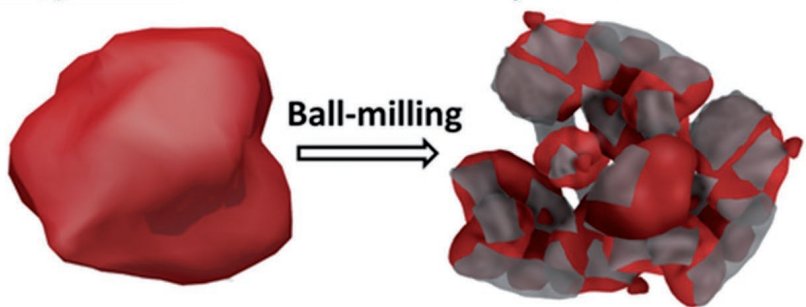

Red Phosphorus P/G Hybrid

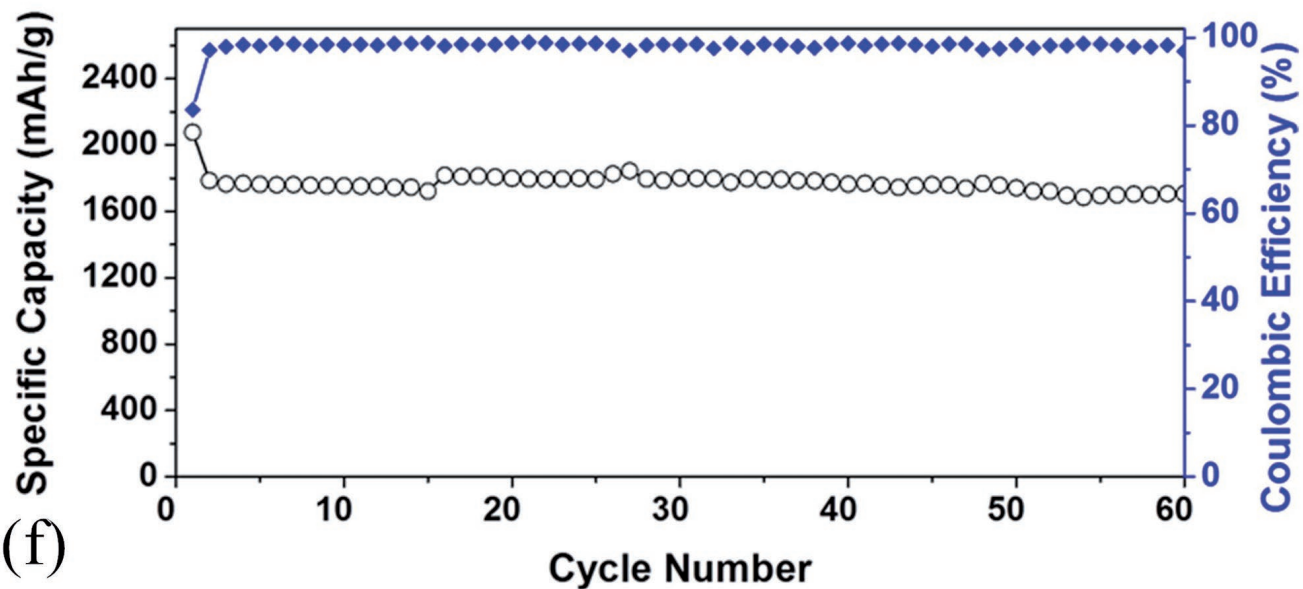

Figure 2. a) TEM and b) SEM images of amorphous RP/C composite. c) Charge-discharge curves and d) cycling performance of RP/C composite. (a-d) Reproduced with permission. ${ }^{12]}$ Copyright 2013, Wiley-VCH. e) Schematic illustration of the synthesis of RP/G composite. f) Cycling performance of RP/G composite under $260 \mathrm{~mA} \mathrm{~g}^{-1}$. (e,f) Reproduced with permission. ${ }^{[35]}$ Copyright 2014, American Chemical Society. 


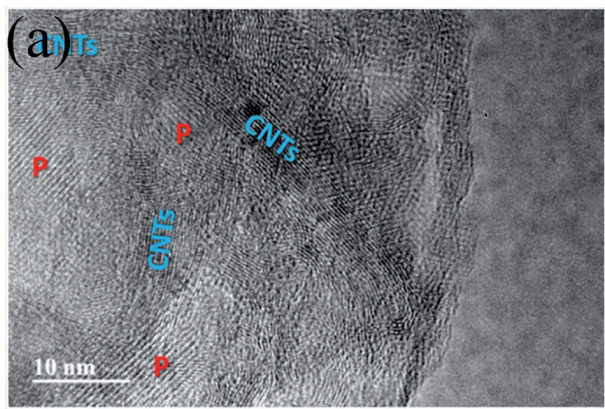

(b)
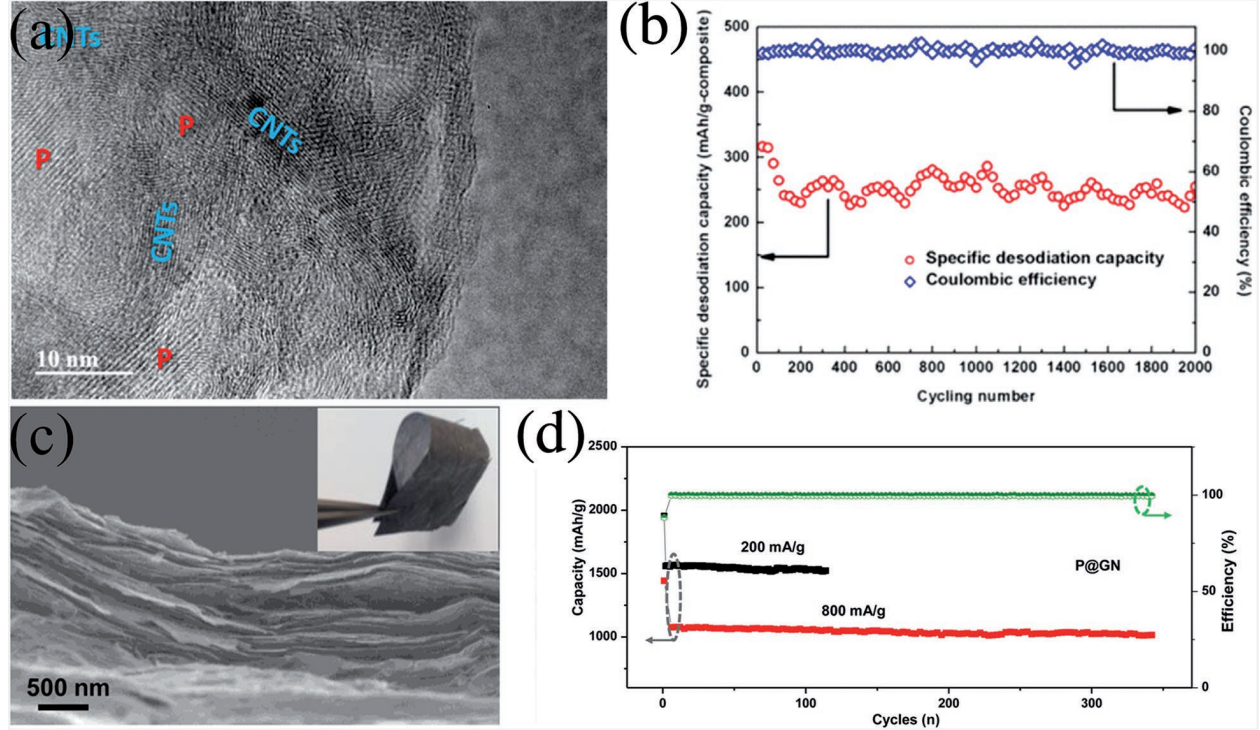

Figure 3. a) TEM image of RP/SWCNT composite. b) Cycling performance and Coulombic efficiency of the RP/SWCNT composite under $2 \mathrm{~A}^{-1}$. (a,b) Reproduced with permission. ${ }^{[19]}$ Copyright 2015, American Chemical Society. c) SEM image of amorphous RP@GN frameworks. d) Cycling performance and Coulombic efficiency of the RP@GN composite. c,d) Reproduced with permission. ${ }^{[38]}$ Copyright 2016, American Chemical Society.

inevitably generate white phosphorus, which is a toxic and very reactive material.

\subsubsection{Other Strategies to Fabricate RP-Based Electrodes}

Currently, ball-milling and vaporization/adsorption are the mainstream approaches used to fabricate RP-based composites for SIB anodes. Although the ball-milling technique is easy and productive, the resultant RP particle size is uneven and not small enough. While the vaporization/adsorption method can reduce the RP particle size to several nanometers, the RP loading level of the composite is normally less than $50 \%$. In light of this, recently, new strategies have been proposed to fabricate RP-based electrode. One representative example is the synthesis of hollow RP nanospheres (HPNs) via a
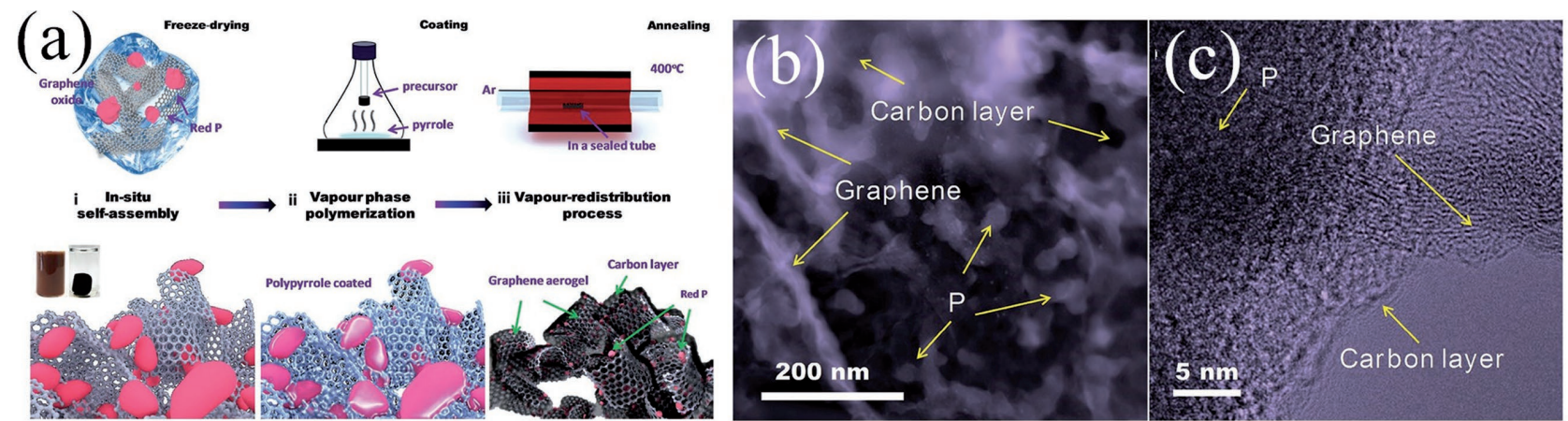
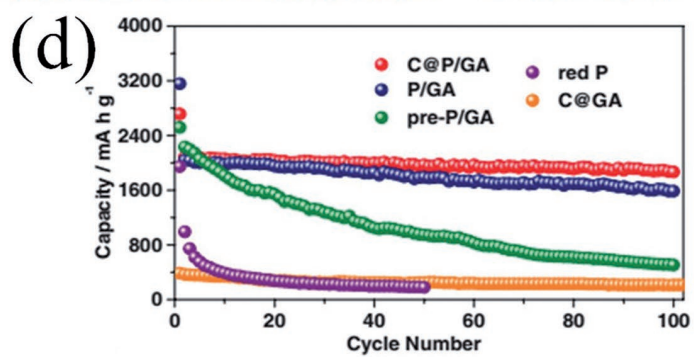

(e)

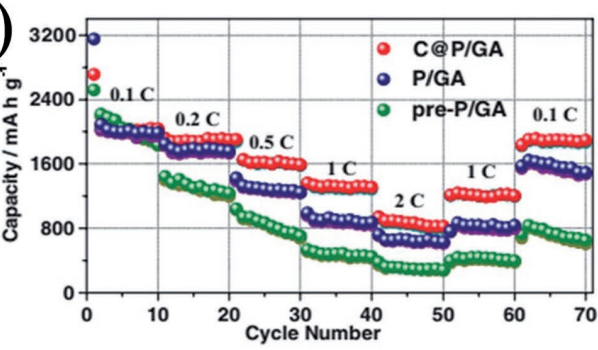

Figure 4. a) Schematic illustration of the synthesis process for C@RP/GA composite in three steps. b,c) TEM (b) and high-resolution TEM (HRTEM) (c) images of C@RP/GA composite.d,e) Cycling performance (at 0.1C) (d) and rate performance (e) of pre-redistributed RP/GA, RP/GA, C@RP/GA, $\mathrm{RP}$, and C@GA composites. Reproduced with permission. ${ }^{[20]}$ Copyright 2016, Wiley-VCH. 
solvothermal method. ${ }^{[39]} \mathrm{Zhu}$ and co-workers ${ }^{[39]}$ demonstrated that, as the reaction between $\mathrm{NaN}_{3}$ and $\mathrm{PCl}_{5}\left(10 \mathrm{NaN}_{3}+2 \mathrm{PCl}_{5} \rightarrow\right.$ $2 \mathrm{P}+10 \mathrm{NaCl}+15 \mathrm{~N}_{2}$ ) proceeds, RP nuclei are assembled around the $\mathrm{N}_{2}$ bubbles, and thus, when the $\mathrm{N}_{2}$ bubbles detach from the $\mathrm{NaN}_{3}$ surface, HPNs are formed. In the report, HPNs were used as anode materials without combining them with carbon. The HPNs, which were $300 \mathrm{~nm}$ in size, exhibited a reversible capacity of $1500 \mathrm{~mA} \mathrm{~h} \mathrm{~g}^{-1}$ at $1300 \mathrm{~mA} \mathrm{~g}^{-1}$ after 80 cycles. Feng and co-workers ${ }^{[40]}$ reported the sodium behavior of core@shell nanostructured RP@Ni-P. The core@shell RP@Ni-P was synthesized by electroless deposition of $\mathrm{Ni}$ on the surfaces of RP particles, and then chemical dealloying was performed in $\mathrm{HCl}$ aqueous solution to control the $\mathrm{Ni}-\mathrm{P}$ shell thickness. As shown in this work, the Ni-P shell plays an important role in the sodium-storage performance of the RP@Ni-P. The Ni-P shell not only facilitates intimate contact between the RP particles and enhances the conductivity of the composite, but also tolerates the large volume expansion during sodiation and maintains a strong electrode structural integrity.

Cui and co-workers ${ }^{[41]}$ proposed a new method to fabricate an $\mathrm{RP} / 3 \mathrm{D}$-carbon framework ( $\mathrm{P} / \mathrm{C}$ composite), in which $\mathrm{P}_{4} \mathrm{O}_{10}$ and poly(ethylene glycol) (PEG) served as the RP and carbon precursors, respectively. $\mathrm{P}_{4} \mathrm{O}_{10}$ and $\mathrm{PEG}$ were first mixed in an oven at $80{ }^{\circ} \mathrm{C}$ and then transferred into an alundum boat and heated at $900{ }^{\circ} \mathrm{C}$. At the high temperature of $900{ }^{\circ} \mathrm{C}$, PEG was carbonized to form a carbon framework, and meanwhile $\mathrm{P}_{4} \mathrm{O}_{10}$ was reduced to RP. Thanks to the volumetric shrinkage from $\mathrm{P}_{4} \mathrm{O}_{10}$ to $\mathrm{RP}$ and the carbon consumption, void space was created, which was large enough for the volume expansion during the RP sodiation. This $\mathrm{P} / \mathrm{C}$ composite delivered a reversible capacity of $920 \mathrm{~mA} \mathrm{~h} \mathrm{~g}^{-1}$ at $200 \mathrm{~mA} \mathrm{~g}^{-1}$ after 160 cycles. Chen and co-workers $^{[31]}$ successfully encapsulated nanosized RP particles in graphene scrolls (P-G) using liquid $\mathrm{N}_{2}$ to assemble $\mathrm{RP}$ and graphene oxide (GO). In the preparation procedure, nanosized RP particles were selected and mixed with GO solution evenly by ultrasonication. When the mixture was subjected to liquid $\mathrm{N}_{2}$, the GO rapidly rolled up due to the quick-freezing process, and the RP was encapsulated inside. After a reduction process on the P-GO with $\mathrm{N}_{2} \mathrm{H}_{4} \cdot \mathrm{H}_{2} \mathrm{O}, \mathrm{P}-\mathrm{G}$ was obtained. The as-prepared $\mathrm{P}-\mathrm{G}$ with an RP content of $52.2 \%$ showed a reversible capacity of $2355 \mathrm{~mA} \mathrm{~h} \mathrm{~g}^{-1}$ (based on the RP) with retention of $92.3 \%$ after 150 cycles.

Recent progress on the materials synthesis and electrochemical performance of RP-based anodes for SIBs is summarized in Table 1. Overall, the ball/hand-milling synthesized RP composite exhibits relatively inferior sodium-storage performance compared to the other methods, which can be ascribed to the uneven and large particle size, ranging from tens of nanometers to several micrometers. ${ }^{[16,42]}$ Compared to the ball-milling method, the vaporization/adsorption technique can reduce RP particles to the nanoscale. Decreased particle size is believed to be an effective way to enhance the electrochemical utilization of the RP, not only because of the short $\mathrm{Na}^{+} /$electron diffusion paths, but also because the small size can alleviate the strain resulting from the RP volume expansion. ${ }^{[41,16,34,42]}$ As shown in Table 1, excellent electrochemical performance can be achieved using the vaporization/adsorption method. Nevertheless, the RP content of most RP-based composites resulting from this technique is typically low (normally below 50\%). The use of a large amount of carbon in the RP composite can certainly reduce the energy density of the electrode. ${ }^{[39]}$

\subsection{Black Phosphorus}

BP has a layered structure similar to that of graphite, featuring large interlayer channels, which are large enough to store sodium ions. ${ }^{[45]}$ Although the theoretical capacities of $\mathrm{RP}$ and BP are the same, BP possesses higher bulk electrical conductivity $\left(\approx 10^{2} \mathrm{~S} \mathrm{~m}^{-1} \mathrm{vS} \approx 10^{-14} \mathrm{~S} \mathrm{~m}^{-1}\right.$ for $\left.\mathrm{RP}\right)$ and higher density $\left(2.69 \mathrm{~g} \mathrm{~cm}^{-3}\right.$ vs $2.36 \mathrm{~g} \mathrm{~cm}^{-3}$ for $\left.\mathrm{RP}\right),{ }^{[11,21]}$ which are favorable for electron transport and realizing high energy densities, indicating that BP could be a better anode material than RP. Researchers have revealed that pure BP can be directly used as an electrode material. The major issue that is obstructing BP application, however, is the complicated synthesis process.

Typically, BP is derived from WP or RP through various methods, such as high-pressure synthesis, ${ }^{[46,47]}$ high-temperature annealing, ${ }^{46,48]}$ and recrystallization in mercury ${ }^{[49]}$ or liquid bismuth. ${ }^{[50]}$ These methods are either time-consuming or use complex apparatus, and also, in some cases, toxic chemicals are involved. A scalable synthesis of BP by a high-energy mechanical-milling method was reported by Park and Sohn. ${ }^{[24]}$ BP can be prepared at ambient temperature and pressure using this method, but a protective gas needs to be provided during the synthesis process. Lang et al. ${ }^{[51]}$ proposed a mineralizerassisted transformation method under simple and safe conditions, although the output of this method was relatively low. To prepare a BP-based anode for SIBs, Komaba and co-workers ${ }^{[47]}$ put RP into a capsule, which was then pressurized to $4.5 \mathrm{GPa}$. After heating at $800{ }^{\circ} \mathrm{C}$ for $1 \mathrm{~h}$, BP was obtained. The asobtained BP was ball milled with acetylene black to fabricate the $\mathrm{BP} / \mathrm{C}$ composite.

Cui and co-workers ${ }^{[21]}$ investigated the sodiation mechanism for BP. Ex situ X-ray diffraction (XRD) results (Figure $5 \mathrm{~d}$ ) revealed that the sodiation process consists of two steps, which include sodium-ion intercalation (between 0.54 and $1.5 \mathrm{~V}$ ) and a further alloying process (below $0.54 \mathrm{~V}$ ). In situ TEM (Figure $5 \mathrm{a}-\mathrm{c}$ ) showed that the large volume change of $\mathrm{BP}(\approx 500 \%)$ mainly occurred along the $y$ and $z$-axial directions. A sandwich-like phosphorene-graphene composite was fabricated, in which the phosphorene was derived from bulk BP particles (Figure 5e,f). The phosphorene-graphene electrode exhibited high reversible capacity and excellent capacity retention at different current densities. Its excellent performance can be attributed to its unique structural design: i) the graphene enhances the electrical conductivity of the whole composite; ii) the 2D nanosheet structure provides short transport distances for sodium ions and electrons; and iii) graphene can serve as an elastic buffer to accommodate the volume changes. Similarly, Shahbazian-Yassar and co-workers ${ }^{[52]}$ found that $\mathrm{Na}^{+}$ions prefer to diffuse along the [100] direction in phosphorene, according to the in situ TEM results. 
Table 1. Recent progress on materials synthesis and electrochemical performance of RP-based anodes for SIBs.

\begin{tabular}{|c|c|c|c|c|c|c|c|}
\hline $\begin{array}{l}\text { Materials } \\
\text { description }\end{array}$ & $\begin{array}{l}\text { Synthesis } \\
\text { method }\end{array}$ & RP size & $\begin{array}{l}\text { RP content } \\
{[\%]}\end{array}$ & Electrolyte & $\begin{array}{l}\text { Cycling } \\
\text { data }^{a)}\end{array}$ & $\begin{array}{c}\text { Rate } \\
\text { capacity }{ }^{b}\end{array}$ & Ref. \\
\hline RP/Super P & Ball milling & - & 70 & $1 \mathrm{M} \mathrm{NaPF}_{6}$ in EC/DEC $(1: 1)$ & $1200 / 60$ th $/ 0.25 \mathrm{C}$ & $640 / 4 \mathrm{C}$ & [34] \\
\hline RP/Super P & Ball milling & $100 \mathrm{~nm}-4 \mu \mathrm{m}$ & 70 & $0.8 \mathrm{M} \mathrm{NaClO}_{4}$ in EC/DEC $(1: 1)$ & $1750 / 30$ th $/ 0.143 \mathrm{C}$ & $1540 / 2.86 \mathrm{C}$ & [12] \\
\hline RP/Graphene & Ball milling & $10-200 \mathrm{~nm}$ & 70 & $\begin{array}{c}1 \mathrm{M} \mathrm{NaClO} \\
\text { in EC/DEC (1:1) } \\
\text { with } 10 \% \text { FEC }\end{array}$ & $1706 / 0.26 C$ & $520 / 5.2 C$ & [35] \\
\hline RP-CNT & Ball milling & $\begin{array}{l}\text { Sub-micrometer to a } \\
\text { few micrometers }\end{array}$ & $\approx 70$ & $\begin{array}{c}1 \mathrm{M} \mathrm{NaClO} \\
\text { with } \mathrm{EC} / \mathrm{DEC}(1: 1) \\
\text { with } 10 \% \mathrm{FEC}\end{array}$ & $1586 / 100$ th $/ 0.52 \mathrm{C}$ & $\approx 850 / 5.2 \mathrm{C}$ & [33] \\
\hline $\mathrm{RP} / \mathrm{CNT}$ & Hand milling & Average $3 \mu \mathrm{m}$ & 30 & $\begin{array}{c}1 \mathrm{M} \mathrm{NaClO} \\
\text { with } 5 \% \mathrm{FEC}\end{array}$ & $1283.3 / 10$ th $/ 0.14 \mathrm{C}$ & - & [28] \\
\hline RP/C@rGO & $\begin{array}{l}\text { Ball milling and } \\
\text { spray drying }\end{array}$ & $\approx 100 \mathrm{~nm}$ & 23.2 & $\begin{array}{c}1 \mathrm{M} \mathrm{NaPF}_{6} \text { in EC/DEC }(1: 1) \\
\text { with } 5 \% \mathrm{FEC}\end{array}$ & 1935/100th/0.1C & $\approx 1200 / 2 C$ & [43] \\
\hline RP@rGO & Vaporization/adsorption & $10-600 \mathrm{~nm}$ & 61.64 & $\begin{array}{c}1 \mathrm{M} \mathrm{NaClO} \text { in } \mathrm{DMC} \text { with } \\
10 \% \mathrm{FEC}\end{array}$ & 1482/300th/1.6C & $219.5 / 4.8 C$ & [13] \\
\hline $\begin{array}{l}\text { RP@N-doped } \\
\text { microporous carbon }\end{array}$ & Vaporization/adsorption & $<1 \mathrm{~nm}$ & 22.6 & $1 \mathrm{M} \mathrm{NaClO}$ in EC/DMC $(1: 1)$ & $\begin{array}{l}\text { 2566/100th/0.15C } \\
1991 / 1000 \text { th/1C }\end{array}$ & $1287 / 9 \mathrm{C}$ & [44] \\
\hline $\begin{array}{l}\text { RP@N-doped } \\
\text { graphene }\end{array}$ & Vaporization/adsorption & - & $\approx 66$ & $1 \mathrm{M} \mathrm{NaPF}_{6}$ in EC/DEC (1:1) & $\begin{array}{l}\approx 2287 / 120 \text { th } / 0.2 \mathrm{C} \\
\approx 1515 / 350 \text { th } / 0.8 \mathrm{C}\end{array}$ & $1226 / 1.5 C$ & [38] \\
\hline RP@CMK-3 & Vaporization/adsorption & - & 31.54 & $1 \mathrm{M} \mathrm{NaClO}_{4}$ in EC/DMC (1:1) & $\begin{array}{l}2188 / 60 \text { th } / 0.52 C \\
1020 / 210 \text { th } / 13 C\end{array}$ & $650 / 25.5 C$ & [29] \\
\hline $\begin{array}{l}\text { RP-single-walled } \\
\text { carbon nanotube }\end{array}$ & Vaporization/adsorption & $5 \mu \mathrm{m}$ & $\approx 40$ & $1 \mathrm{M} \mathrm{NaClO}$ in FEC/DMC $(1: 1)$ & $\begin{array}{l}\text { 1275/200th } / 0.5 \mathrm{C} \\
550 / 2000 \text { th } / 2 \mathrm{C}\end{array}$ & $750 / 2 C$ & [19] \\
\hline $\begin{array}{l}\text { C@RP/graphene } \\
\text { aerogel }\end{array}$ & Vaporization/adsorption & $10-20 \mathrm{~nm}$ & 47.2 & $\begin{array}{c}1 \mathrm{M} \mathrm{NaClO} \\
\text { in EC/DEC (1:1) } \\
\text { with } 10 \% \mathrm{FEC}\end{array}$ & $\begin{array}{l}1867 / 100 \text { th } / 0.26 \mathrm{C} \\
1095.5 / 200 \text { th } / 2.6 \mathrm{C}\end{array}$ & $1861 / 5.2 \mathrm{C}$ & [20] \\
\hline $\begin{array}{l}\mathrm{RP} / \mathrm{N} \text {-doped carbon } \\
\text { nanofiber }\end{array}$ & Vaporization/adsorption & - & 27.5 & $\begin{array}{c}1 \mathrm{M} \mathrm{NaClO} \\
\text { in EC/DEC (1:1) } \\
\text { with } 10 \% \text { FEC }\end{array}$ & $2658 / 55$ th $/ 0.1 \mathrm{C}$ & - & [32] \\
\hline $\begin{array}{l}\text { Hollow RP } \\
\text { nanospheres }\end{array}$ & $\begin{array}{l}\text { Wet-chemical } \\
\text { synthesis }\end{array}$ & $\approx 300 \mathrm{~nm}$ & 100 & $\begin{array}{c}1 \mathrm{M} \mathrm{NaClO}_{4} \text { in EC/DMC (1:1) } \\
\text { with } 5 \% \mathrm{FEC}\end{array}$ & $\begin{array}{c}1675 / 80 \text { th/1.3C } \\
969.8 / 600 \text { th } / 2.6 \mathrm{C}\end{array}$ & $278.4 / 10.4 C$ & [39] \\
\hline $\begin{array}{l}\text { Core@shell struc- } \\
\text { tured RP@Ni-P }\end{array}$ & $\begin{array}{l}\text { Electroless deposition } \\
\text { with chemical dealloying }\end{array}$ & $<200 \mathrm{~nm}$ & 93.83 & $1 \mathrm{M} \mathrm{NaClO}$ in $\mathrm{PC}$ with $5 \%$ FEC & $\begin{array}{c}\text { 1339/200th/0.26C } \\
436 / 2000 \text { th } / 5 \mathrm{C}\end{array}$ & $522 / 5.2 \mathrm{C}$ & [40] \\
\hline $\begin{array}{l}\mathrm{RP} / 3 \mathrm{D} \text { carbon } \\
\text { framework }\end{array}$ & $\begin{array}{l}\text { Carbothermic } \\
\text { reduction }\end{array}$ & $\approx 10 \mathrm{~nm}$ & 36 & $\begin{array}{c}1 \mathrm{M} \mathrm{NaPF}_{6} \text { in EC/DEC }(1: 1) \\
\text { with } 10 \% \text { FEC }\end{array}$ & $2555 / 160$ th $/ 0.2 \mathrm{C}$ & $944 / 10 \mathrm{C}$ & [41] \\
\hline $\begin{array}{l}\mathrm{RP} \text { in graphene } \\
\text { scrolls }\end{array}$ & Quick-freezing process & $100-150 \mathrm{~nm}$ & 52.2 & $\begin{array}{c}1 \mathrm{M} \mathrm{NaClO}_{4} \text { in EC/DEC (1:1) } \\
\text { with } 5 \% \mathrm{FEC}\end{array}$ & $2173.7 / 0.25 \mathrm{C}$ & $1084 / 4 C$ & [31] \\
\hline
\end{tabular}

a) The cycling data are summarized as capacity/corresponding cycle number/corresponding current density. The specific capacity was calculated based on the weight of phosphorus. The unit of capacity is $\mathrm{mA} \mathrm{h} \mathrm{g}^{-1}$. For all the data, $1 \mathrm{C}$ equals $1000 \mathrm{~mA} \mathrm{~g}^{-1}$; b) The rate capability is summarized as capacity/corresponding current density. The

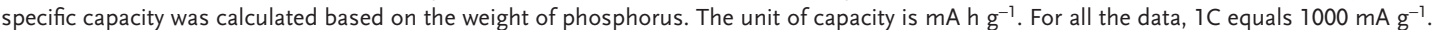

Dahbi et al. ${ }^{[4]}$ studied the influence of electrolyte additives on the electrochemical performance of BP. A BP electrode with a fluoroethylene carbonate/vinylene carbonate (FEC/VC) additive always exhibits better results than its counterpart without. Further surface characterization techniques revealed that the FEC/VC additive facilitates the formation of a more stable and thinner solid electrolyte interphase (SEI) layer. This SEI layer creates lower resistance on the BP surface and can protect the electrolyte from decomposition. Therefore, a higher specific capacity and Coulombic efficiency were obtained.

The advantages of the orthorhombic BP are threefold: thermodynamic stability, good electrical conductivity, and the layered crystal structure with a larger interlayer channel size than that of graphite. Compared to the commercially available
RP, however, BP with its complicated synthesis process is still unsuitable for further application.

\section{Metal Phosphides}

Phosphorus has poor conductivity, while metals such as $\mathrm{Cu}$, $\mathrm{Fe}$, and $\mathrm{Co}$ are conductive. Combining $\mathrm{P}$ with these metals to form metal phosphides is expected to improve the conductivity of the composite. ${ }^{[53-57]}$ Conductive metal is formed during the charge-discharge processes and can serve as an electron-transport channel to enhance the conductivity of the electrode materials. ${ }^{[55]}$ What is more, it is believed that the presence of the secondary ingredient dilutes the concentration of $\mathrm{P}$ species and can buffer its volume changes during repeated 

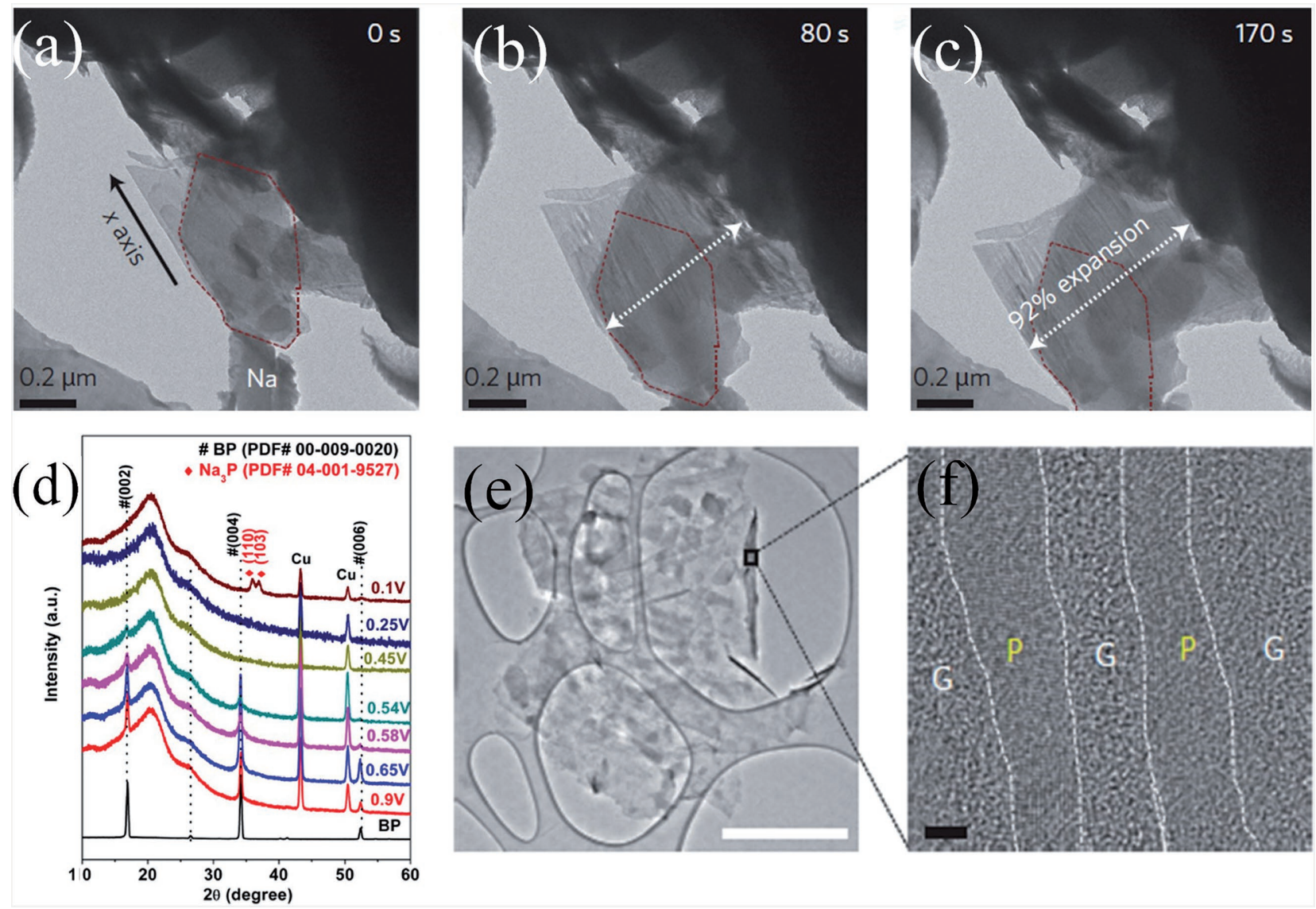

Figure 5. a-c) Time-lapse TEM images of sodiation in black. d) Ex situ XRD patterns of black phosphorus taken before charging and after charging down to different voltages. e) TEM image of the phosphorene-graphene hybrid. Scale bar, $2 \mu \mathrm{m}$. f) HRTEM image of a cross-section of the phosphorene-graphene hybrid. Reproduced with permission. ${ }^{[21]}$ Copyright 2015, Nature Publishing Group.

sodiation and desodiation. ${ }^{[54,55,58,59]}$ For some metal phosphides, metal and phosphorus elements can be converted back to the starting metal phosphide during the desodiation process, thus healing the cracks induced by the sodiation and alleviating the pulverization. ${ }^{[54,58-60]}$

\subsection{Phosphidation Method}

Metal phosphides are usually derived from elemental metals or metal oxides. To prepare metal phosphides, two main phosphidation methods are proposed: ball milling and $\mathrm{NaH}_{2} \mathrm{PO}_{2}$ phosphidation.

Because of its facility and high productivity, ball milling is widely used to fabricate metal phosphide anode materials. For example, Chou and co-workers ${ }^{[59]}$ prepared a $\mathrm{Sn}_{4+x} \mathrm{P}_{3} @$ (Sn-P) compound through ball milling, using red phosphorus and tin powder (in the molar ratio of 3:5) as the starting materials. The obtained product had a particle size of $30-80 \mathrm{~nm}$. It should be noted that the stoichiometric ratio of the starting materials is a crucial parameter in the ballmilling process. In Chou's experiment, ${ }^{[59]}$ when a $\mathrm{Sn}: \mathrm{P}$ ratio of 4:3 was used, pure $\mathrm{Sn}_{4} \mathrm{P}_{3}$ was harvested. Similarly, ternary metal phosphides can also be synthesized using this method.
Ouyang and co-workers ${ }^{[61]}$ reported a $\mathrm{ZnGeP}_{2} / \mathrm{C}$ composite synthesized using the ball-milling method. $\mathrm{Zn}, \mathrm{Ge}$, and red $\mathrm{P}$ were first subjected to high-energy ball milling to form $\mathrm{ZnGeP}_{2}$. Then, high-energy planetary milling of the as-prepared $\mathrm{ZnGeP}_{2}$ and Super $\mathrm{P}$ was conducted to prepare the final $\mathrm{ZnGeP}_{2} / \mathrm{C}$.

$\mathrm{NaH}_{2} \mathrm{PO}_{2}$ can chemically transform the precursors into metal phosphides at a temperature around $300{ }^{\circ} \mathrm{C}$ without destroying the precursor nanostructure. ${ }^{[62]}$ This means that $\mathrm{NaH}_{2} \mathrm{PO}_{2}$ phosphidation can be a good way to prepare nanostructured metal phosphides. ${ }^{[62-64]}$ Wang and co-workers ${ }^{[62]}$ reported pomegranate-structured $\mathrm{Sn}_{4} \mathrm{P}_{3} @$ spheres synthesized by the $\mathrm{NaH}_{2} \mathrm{PO}_{2}$ phosphidation method. In this experiment, $\mathrm{SnO}_{2} @ \mathrm{C}$ “pomegranates” prepared by the aerosol-spray-pyrolysis method were hand milled with $\mathrm{NaH}_{2} \mathrm{PO}_{2}$, and the mixture was then annealed at a temperature of $280^{\circ} \mathrm{C}$ for $10 \mathrm{~min}$. After cooling down and washing the product, pomegranate-structured $\mathrm{Sn}_{4} \mathrm{P}_{3} @$ spheres were obtained. Other nanostructured metal phosphides, such as $\mathrm{Cu}_{3} \mathrm{P}$ nanowires $(\mathrm{CPNW})^{[65]}$ and core-shell CoP@C polyhedra, ${ }^{[18]}$ were also fabricated using this method.

Apart from the above phosphidation methods, other methods, such as high-temperature annealing, ${ }^{[66]}$ solvothermal phosphidation, ${ }^{[67]}$ and the solution chemistry method, ${ }^{[68]}$ were also reported. 

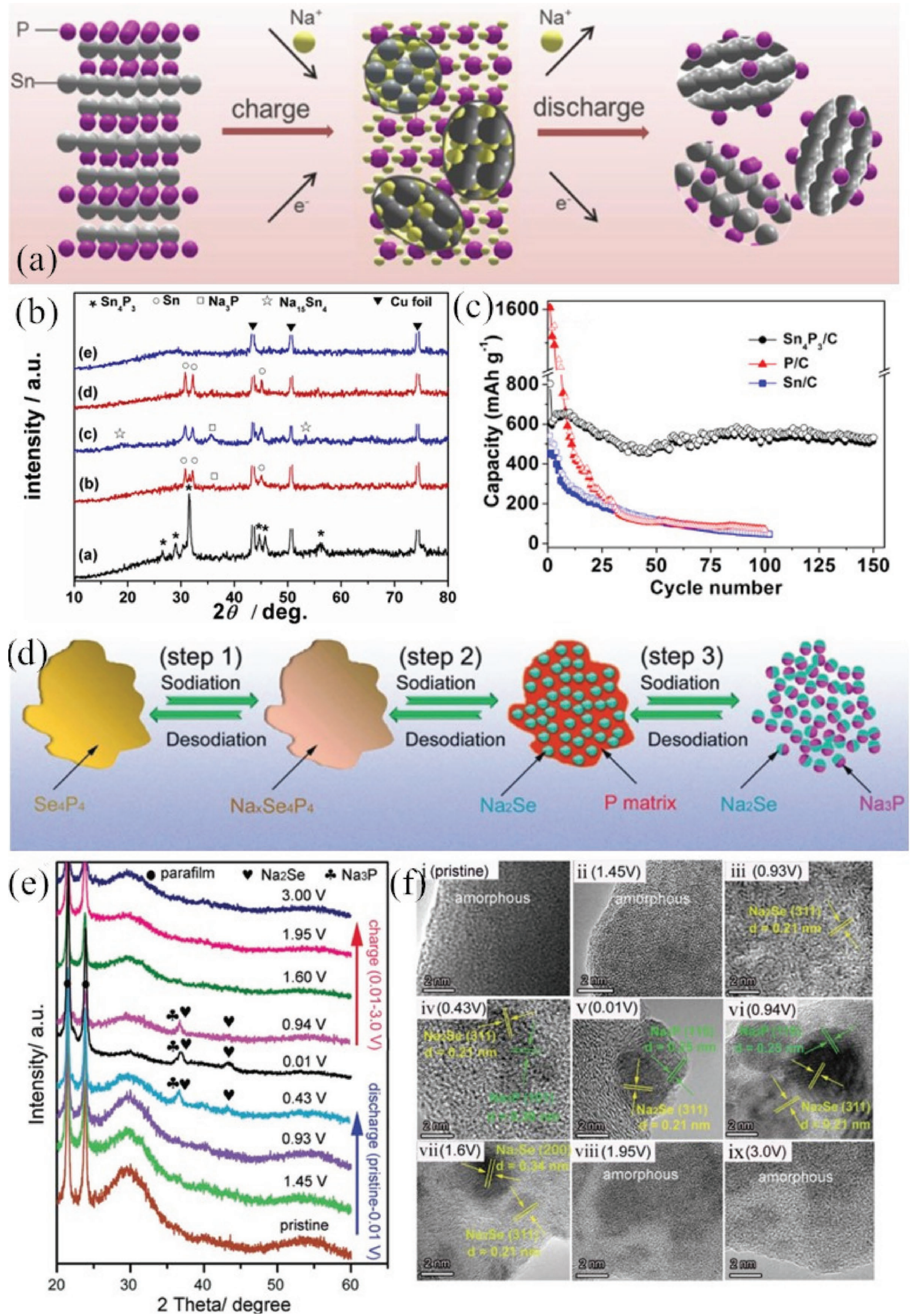


\subsection{Reaction Mechanism}

To date, reported P-based alloy compounds for SIBs include $\mathrm{Co}-\mathrm{P}(\mathrm{CoP}),{ }^{[56]} \mathrm{Cu}-\mathrm{P}\left(\mathrm{CuP}_{2}, \mathrm{Cu}_{3} \mathrm{P}\right),{ }^{[65,69]} \mathrm{Fe}-\mathrm{P}\left(\mathrm{FeP}, \mathrm{FeP}_{4}\right),{ }^{[57,70]}$ $\mathrm{Ni}-\mathrm{P}\left(\mathrm{NiP}_{3}\right),{ }^{[71]} \mathrm{Se}-\mathrm{P}\left(\mathrm{Se}_{4} \mathrm{P}_{4}\right),{ }^{[54]} \mathrm{Sn}-\mathrm{P}\left(\mathrm{Sn}_{4} \mathrm{P}_{3}, \mathrm{SnP}_{3}\right),{ }^{[58,72]}$ and Ge-P $\left(\mathrm{GeP}_{5}\right){ }^{[73]}$ These metal phosphides can be broadly divided into two types: metal inactive and metal active, depending on whether the metal in the metal phosphide is electrochemically active or not. The metal-inactive metal phosphides include Co-P (CoP), Cu-P ( $\left.\mathrm{CuP}_{2}, \mathrm{Cu}_{3} \mathrm{P}\right), \mathrm{Fe}-\mathrm{P}\left(\mathrm{FeP}, \mathrm{FeP}_{4}\right)$, and $\mathrm{Ni}-\mathrm{P}$ $\left(\mathrm{NiP}_{3}\right)$. The presence of the highly conductive metal in this kind of metal phosphide can improve the electrical conductivity of these compounds. ${ }^{[55]}$ The capacity of these compounds is only contributed by the $\mathrm{P}$, however, since the metal is totally inactive. Their charge-discharge mechanism can be summarized by the following conversion reaction (Equation (1)):

$\mathrm{MP}_{x}+3 x \mathrm{Na}^{+}+3 x \mathrm{e}^{-} \leftrightarrow x \mathrm{Na}_{3} \mathrm{P}+\mathrm{M}$

Unlike the previous type, the metal in the metal-active type is electrochemically active (e.g., Se-P, Sn-P, and Ge-P). Apart from the conversion reaction, an alloying reaction also takes place in these metal-active metal phosphides to form $\mathrm{Na}_{\gamma} \mathrm{M}$ :

$\mathrm{P}_{x}+(3 x+\gamma) \mathrm{Na}^{+}+(3 x+\gamma) \mathrm{e}^{-} \leftrightarrow x \mathrm{Na}_{3} \mathrm{P}+\mathrm{Na}_{\gamma} \mathrm{M}$

Because both the metal and the $\mathrm{P}$ react with sodium ions, the metal-active metal phosphides usually possess higher theoretical capacities than the metal-inactive ones. The theoretical capacity depends on the species and content of the metal in the metal phosphides.

Ex situ XRD and TEM are usually used to reveal the sodiumstorage mechanism of metal phosphides. Electrodes at different discharge-charge states are disassembled and examined to investigate the phase and structure changes during the sodiation/desodiation process. For example, $\mathrm{Cu}_{3} \mathrm{P}$ electrodes were tested by XRD. ${ }^{[65]}$ As shown in the results, during the sodiation process, the peak corresponding to $\mathrm{Cu}_{3} \mathrm{P}$ gradually diminished and totally disappeared during the discharge. Meanwhile, a new peak corresponding to the (103) planes of $\mathrm{Na}_{3} \mathrm{P}$ emerged, and the intensity of two peaks arising from the $\mathrm{Cu}$ content was enhanced, indicating that the $\mathrm{Cu}_{3} \mathrm{P}$ was transformed to $\mathrm{Na}_{3} \mathrm{P}$ and $\mathrm{Cu}$. For the desodiation process, the reverse composition changes were observed. Therefore, a conversion mechanism for $\mathrm{Cu}_{3} \mathrm{P}$ was proposed: $\mathrm{Cu}_{3} \mathrm{P}+3 \mathrm{Na} \leftrightarrow \mathrm{Na}_{3} \mathrm{P}+3 \mathrm{Cu}$. Similarly, $\mathrm{Oh}$ and co-workers ${ }^{[53]}$ also investigated the sodiation mechanism for $\mathrm{Sn}_{4} \mathrm{P}_{3}$ using ex situ XRD and ex situ TEM. Upon sodiation, the intensity of the XRD peak for $\mathrm{Sn}_{4} \mathrm{P}_{3}$ decreased, and crystalline $\mathrm{NaSn}$ and $\mathrm{Na}_{15} \mathrm{Sn}_{4}$ were observed in the TEM images, indicating that an amorphous $\mathrm{Na}_{x} \mathrm{P}$ phase was formed. On desodiation, the intensity of the XRD peak for $\mathrm{Sn}_{4} \mathrm{P}_{3}$ increased. This suggests that the conversion reaction of $\mathrm{Sn}_{4} \mathrm{P}_{3}$ to $\mathrm{Na}_{x} \mathrm{P}$ and $\mathrm{Na}_{15} \mathrm{Sn}_{4}$ is reversible. Recently, Chen and co-workers ${ }^{[54]}$ proposed an Na-storage reaction mechanism for $\mathrm{Se}_{4} \mathrm{P}_{4}$, using ex situ XRD, ex situ TEM, and in situ Raman techniques.

\subsection{Metal-Active Phosphides}

Because of their higher theoretical capacity than metal-inactive phosphides, metal-active phosphides have attracted considerable attention, especially tin phosphides. Yang and co-workers ${ }^{[72]}$ reported an early investigation of $\mathrm{Sn}_{4} \mathrm{P}_{3} . \mathrm{Sn}_{4} \mathrm{P}_{3} / \mathrm{C}$ composite was synthesized using the ball-milling method. Ex situ XRD patterns of $\mathrm{Sn}_{4} \mathrm{P}_{3} / \mathrm{C}$ at different charge and discharge states indicated the presence of $\mathrm{Na}_{3} \mathrm{P}$ and $\mathrm{Na}_{15} \mathrm{Sn}_{4}$, proving that $\mathrm{Sn}$ is electrochemically active in the $\mathrm{Sn}_{4} \mathrm{P}_{3} / \mathrm{C}$ (Figure 6a,b). This $\mathrm{Sn}_{4} \mathrm{P}_{3} / \mathrm{C}$ demonstrated a high reversible capacity of $850 \mathrm{~mA} \mathrm{~h} \mathrm{~g}^{-1}$ and stable cycling performance, while the $\mathrm{Sn} / \mathrm{C}$ and $\mathrm{P} / \mathrm{C}$ composites showed poor capacity retention $(\approx 60 \%$ capacity loss in the first 25 cycles) (Figure 6c). Moreover, most of the reversible capacity was delivered at the low potential of $\approx 0.3 \mathrm{~V}$, meaning that $\mathrm{Sn}_{4} \mathrm{P}_{3}$ should be a promising anode material for high-energy SIBs. After this, more efforts were made to develop the potential of $\mathrm{Sn}_{4} \mathrm{P}_{3}$. For example, Liu et al. reported yolk-shell $\mathrm{Sn}_{4} \mathrm{P}_{3} @ \mathrm{C}$ nanospheres, in which the $\mathrm{Sn}_{4} \mathrm{P}_{3}$ nanoparticles were surrounded by a carbon shell. ${ }^{[14]}$ The void space between the $\mathrm{Sn}_{4} \mathrm{P}_{3}$ particles and the carbon shell was rationally designed to accommodate the volume expansion of $\mathrm{Sn}_{4} \mathrm{P}_{3}$. Therefore, the presence of an internal void space prevents the nanostructure of this anode material from being destroyed and the SEI layer on the outside surface from being disrupted. Thanks to this unique structure, high reversible capacity, excellent rate performance, and outstanding cycling stability were obtained.

Similar to tin phosphides, selenium phosphide was also proposed as a new metal-active phosphide, by Chen and co-workers in 2017. ${ }^{[54]} \mathrm{A}$ series of characterization results revealed that the sodiation process of $\mathrm{Se}_{4} \mathrm{P}_{4}$ consists of three steps: i) $\mathrm{Se}_{4} \mathrm{P}_{4}$ is first transformed to amorphous $\mathrm{Na}_{x} \mathrm{Se}_{4} \mathrm{P}_{4}$; ii) then $\mathrm{Na}_{2} \mathrm{Se}$ and elemental $\mathrm{P}$ are formed from $\mathrm{Na}_{x} \mathrm{Se}_{4} \mathrm{P}_{4}$; and iii) finally, elemental $\mathrm{P}$ further reacts with $\mathrm{Na}^{+}$to form $\mathrm{Na}_{3} \mathrm{P}$ (Figure $6 \mathrm{~d}-\mathrm{f}$ ). During the sodiation process, $20 \mathrm{Na}^{+}$ions are involved, giving a high theoretical capacity of $1217 \mathrm{~mA} \mathrm{~h} \mathrm{~g}^{-1}$. This ball-millingsynthesized $\mathrm{Se}_{4} \mathrm{P}_{4}$ has a reversible capacity of $1048 \mathrm{~mA} \mathrm{~h} \mathrm{~g}^{-1}$ $\left(\approx 86 \%\right.$ of the theoretical capacity), and $804 \mathrm{~mA} \mathrm{~h} \mathrm{~g}^{-1}$ is retained after 60 cycles. It is believed that the excellent cycling stability is attributable to the synergistic effects: during the sodiation process, the elemental $\mathrm{P}$ can prevent the aggregation of $\mathrm{Na}_{2} \mathrm{Se}$, while the semiconductive $\mathrm{Na}_{2}$ Se provides conducting pathways to facilitate the reactions of the insulating P.

\subsection{Metal-Inactive Phosphides}

There is no doubt that the use of an electrochemically inactive metal, such as $\mathrm{Cu}, \mathrm{Fe}$, or Ni, can decrease the theoretical

Figure 6. a) Schematic illustration of the Na-storage mechanism in $\mathrm{Sn}_{4} \mathrm{P}_{3}$ electrode. b) Ex situ XRD patterns of the $\mathrm{Sn}_{4} \mathrm{P}_{3} / \mathrm{C}$ electrode at different charge and discharge states. c) Comparison of the reversible capacities of $\mathrm{Sn}_{4} \mathrm{P}_{3} / \mathrm{C}, \mathrm{Sn} / \mathrm{C}$, and $\mathrm{P} / \mathrm{C}$ electrodes at a current density of $100 \mathrm{~mA} \mathrm{~g}^{-1}$. a-c) Reproduced with permission. ${ }^{[60]}$ Copyright 2014, American Chemical Society. d) Schematic illustration of the sodiation/desodiation of Se ${ }_{4} \mathrm{P}_{4}$. e) Ex situ XRD patterns of $\mathrm{Se}_{4} \mathrm{P}_{4}$ during the electrochemical reaction with $\mathrm{Na}$. $\mathrm{f}$ ) Ex situ HRTEM images of the electrode at different states in the discharge/charge process. $\mathrm{d}-\mathrm{f}$ ) Reproduced with permission. ${ }^{[54]}$ Copyright 2016, Wiley-VCH. 


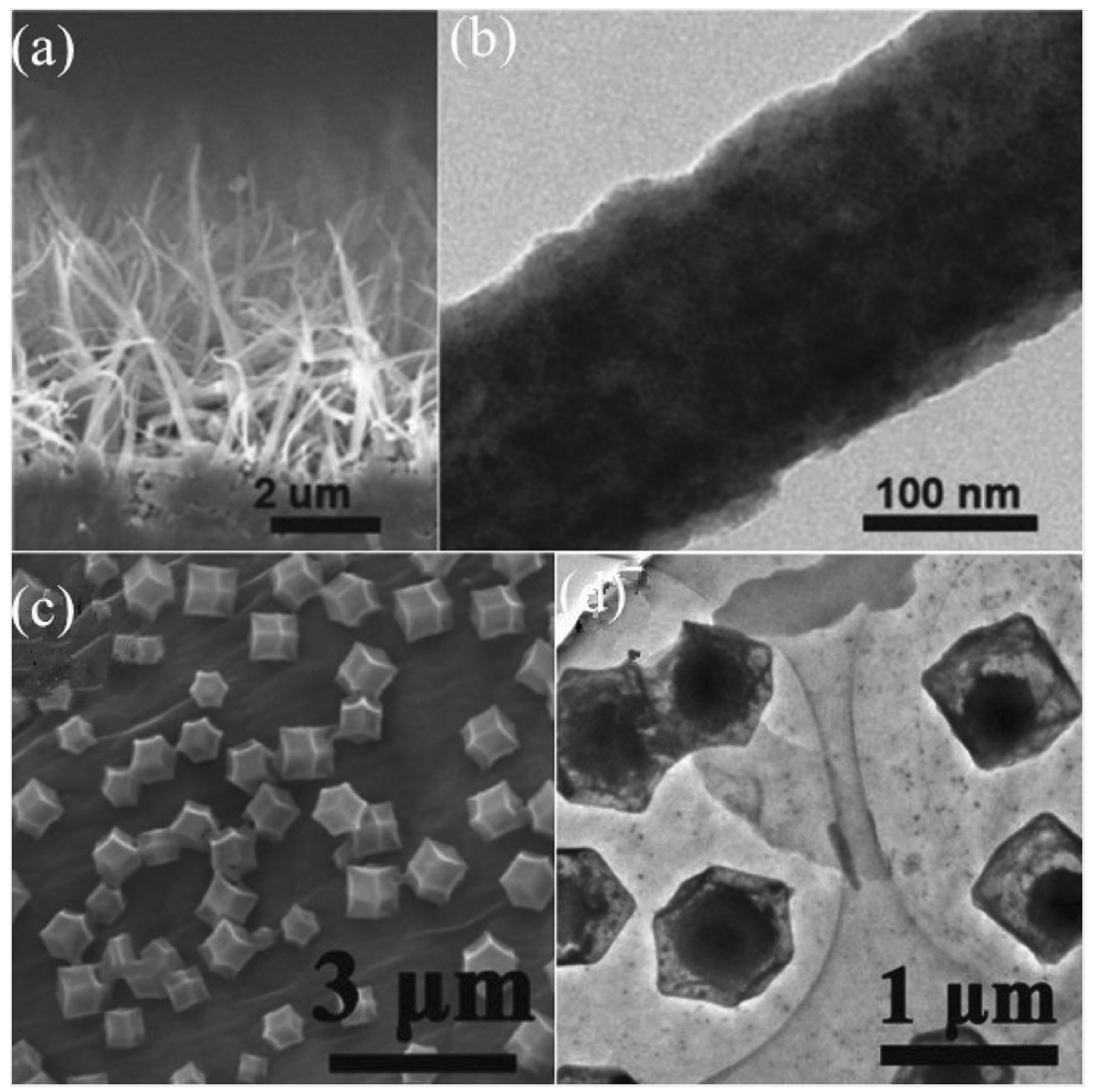

Figure 7. a,b) SEM (a) and TEM (b) images of CPNWs. a,b) Reproduced with permission. ${ }^{[65]}$ Copyright 2016, Wiley-VCH. c,d) SEM (c) and TEM (d) images of the core-shell CoP@C polyhedra anchored on reduced graphene oxide. c,d) Reproduced with permission. ${ }^{[18]}$ Copyright 2017, Elsevier. conductivity of $\mathrm{rGO}$ and the void space in the core-shell structure to buffer the volume expansion.

To fully achieve the potential of both types of metal phosphides, most efforts have been devoted to modifying the electrochemical properties of the electrode. Recent progress has led to great improvements in metal phosphide. As summarized in Table 2, one effective method is tuning the microstructure. Nanosized particles not only provide short diffusion paths for sodium ions and electrons to enhance the rate capability, but also have a large surface area to guarantee adequate contact between the electrode and the electrolyte. ${ }^{[14,65,17]}$ Another method is synthesizing carbon composite. ${ }^{[55,58]}$ Much research work has shown that combining metal phosphides with carbon can effectively enhance the conductivity of the metal phosphides. ${ }^{[55,67]}$ As a supporting material, the carbon matrix can also prevent the aggregation of the homogeneously dispersed metal phosphide nanoparticles and interconnect the separate particles. The initial Coulombic efficiency of many metal phosphide anodes is still less than 70\%, which is mainly due to the formation of the SEI layer. Electrolyte research has revealed that the electrolyte additive FEC can help to form a more stable SEI layer, but it also reduces the initial Coulombic efficiency. ${ }^{[62]}$ capacity of metal phosphides, since the metal makes no contribution to the capacity of these metal phosphides. Even so, the advantages of the metal-inactive type phosphides are also obvious: i) the metals are highly conductive, which is helpful for fully utilizing the P capacity; ii) these metal-inactive phosphides experience relatively less volume expansion than the metal-active type because no volume expansion occurs in the inactive metals.

$\mathrm{Cu}_{3} \mathrm{P}$ nanowires $(\mathrm{CPNWs})^{[65]}$ grown on a copper current collector were reported by Yan and co-workers. This nanostructured $\mathrm{Cu}_{3} \mathrm{P}$ exhibited outstanding cycling stability. This excellent cycling ability was ascribed to the unique $1 \mathrm{D}$ features of CPNW and its small size, which are favorable for electrolyte penetration, electron transportation, and strain accommodation (Figure 7a,b). To further verify this, CPNWs with different sizes were synthesized, and it was found that the CPNWs with large size suffered from fast capacity decay. Yin and co-workers ${ }^{[18]}$ fabricated core-shell CoP@C polyhedra anchored on reduced graphene oxide (rGO) from core-shell Co@C structures derived from zeolitic imidazolium framework-67. The core-shell-structured CoP@C nanoparticles were homogeneously dispersed on the surface of rGO (Figure 7c,d). When used as an anode material for SIBs, this composite exhibited excellent rate performance and long cycling life, which can be explained by the good

\section{Summary and Perspectives}

$\mathrm{P}$ has the largest theoretical capacity among the potential anode materials for SIBs, but the poor electrical conductivity of RP has impeded its application. Therefore, the use of carbon is important in RP-based electrodes in order to enhance its conductivity. The large amount of carbon that is needed, however, can also decrease the energy density of the RP electrode. To develop a high-energy RP-based electrode, further research should focus on improving the RP loading level. For example, the advanced vapor-redistribution strategy reported by our group can achieve a high RP loading level of $\approx 50 \%,{ }^{[20]}$ whereas the RP contents of most RP/C composites prepared by the traditional vaporization/adsorption technique are $\approx 30 \%$. Unlike RP, BP has a high electrical conductivity of $\approx 10^{2} \mathrm{~S} \mathrm{~m}^{-1}$, meaning that a conductive matrix such as carbon is not necessary in the BP electrode. The main obstacle for BP is its complicated synthesis process, for which extremely high temperature and pressure are required. Thus, more efforts need to be made to develop a new, simple method to synthesize BP in the future.

For metal phosphides, although the progress made in the past several years is significant, further research is still highly desirable: i) new metal-active phosphides should be developed. Metal-active phosphides represent a promising type of high-energy-density anode material. To date, however, only 
Table 2. Recent progress on the material synthesis and electrochemical performance of metal phosphide anodes for SIBs.

\begin{tabular}{|c|c|c|c|c|c|c|}
\hline Materials description & $\begin{array}{l}\text { Synthesis } \\
\text { method }\end{array}$ & $\begin{array}{l}\text { Initial Coulombic } \\
\text { efficiency }\end{array}$ & Electrolyte & $\begin{array}{l}\text { Cycling } \\
\text { data }^{a)}\end{array}$ & $\begin{array}{c}\text { Rate } \\
\text { capability b) }\end{array}$ & Ref. \\
\hline \multicolumn{7}{|l|}{ Tin phosphide } \\
\hline $\mathrm{SnP}_{3} / \mathrm{C}$ & Ball milling & $71.2 \%$ & $1 \mathrm{M} \mathrm{NaClO}_{4}$ in FEC/DMC $(1: 1)$ & $\approx 800 / 150$ th $/ 0.15 \mathrm{C}$ & $400 / 2.5 C$ & [58] \\
\hline $\mathrm{Sn}_{4+x} \mathrm{P} 3 @(\mathrm{Sn}-\mathrm{P})$ & Ball milling & $\approx 72 \%$ & $1 \mathrm{M} \mathrm{NaClO}$ in EC:DEC (1:1) with 5\% FEC & $465 / 100$ th $/ 0.1 \mathrm{C}$ & $58.2 / 10 \mathrm{C}$ & [59] \\
\hline $\mathrm{Sn}_{4} \mathrm{P}_{3}$ & Ball milling & $\approx 73 \%$ & $1 \mathrm{M} \mathrm{NaClO}$ in EC:DEC (1:1) with 5\% FEC & $650 / 100$ th $/ 0.1 \mathrm{C}$ & - & [53] \\
\hline $\mathrm{Sn}_{4} \mathrm{P}_{3} / \mathrm{C}$ & Ball milling & $77.3 \%$ & $1 \mathrm{M} \mathrm{NaPF}_{6}$ in $\mathrm{EC} / \mathrm{DEC}$ with $5 \% \mathrm{FEC}$ & $\approx 364 / 150$ th $/ 0.1 \mathrm{C}$ & $244 / 1 C$ & [60] \\
\hline $\mathrm{Sn}_{4} \mathrm{P}_{3} / \mathrm{rGO}$ & Solvothermal phosphidation & $46.6 \%$ & $1 \mathrm{M} \mathrm{NaClO}_{4}$ in PC with $5 \% \mathrm{FEC}$ & $656 / 100$ th $/ 0.1 \mathrm{C}$ & $391 / 2 C$ & [67] \\
\hline $\mathrm{Sn}_{4} \mathrm{P}_{3}$ nanoparticles & Solvothermal phosphidation & $\approx 53 \%$ & $1 \mathrm{M} \mathrm{NaClO}$ in $\mathrm{EC} / \mathrm{DEC}$ with $5 \% \mathrm{FEC}$ & $305 / 10$ th $/ 0.05 \mathrm{C}$ & - & [74] \\
\hline $\begin{array}{l}\text { Yolk-shell } \mathrm{Sn}_{4} \mathrm{P}_{3} @ \mathrm{C} \\
\text { nanospheres }\end{array}$ & Solvothermal phosphidation & $43.8 \%$ & $1 \mathrm{M} \mathrm{NaClO}_{4}$ in PC with $5 \%$ FEC & $515 / 50$ th $/ 0.1 \mathrm{C}$ & $421 / 3 C$ & [14] \\
\hline $\mathrm{Sn}_{4} \mathrm{P}_{3} @ \mathrm{C}$ spheres & $\mathrm{NaH}_{2} \mathrm{PO}_{2}$ phosphidation & $\begin{array}{l}90.7 \% \\
72.7 \% \\
59.8 \%\end{array}$ & $\begin{array}{l}1 \mathrm{M} \mathrm{NaPF} 6 \text { in dimethoxyethane (DME) } \\
1 \mathrm{M} \mathrm{NaPF}_{6} \text { in EC/DMC } \\
1 \mathrm{M} \mathrm{NaPF}_{6} \text { in EC/DMC with } 10 \% \mathrm{FEC}\end{array}$ & $\begin{array}{l}\text { 700/120th } / 0.1 \mathrm{C} \\
380 / 110 \text { th } / 0.1 \mathrm{C} \\
580 / 120 \text { th } / 0.1 \mathrm{C}\end{array}$ & - & [62] \\
\hline $\mathrm{Sn}_{4} \mathrm{P}_{3}$ nanotops & Solution chemistry method & $72.7 \%$ & $1 \mathrm{M} \mathrm{NaClO}$ in PC with 5\% FEC & $\begin{array}{c}\approx 490 / 80 \text { th } / 0.2 \mathrm{C} \\
400 / 80 \text { th } / 0.5 \mathrm{C}\end{array}$ & $339 / 1 C$ & [68] \\
\hline \multicolumn{7}{|l|}{ Cobalt phosphide } \\
\hline CoP particle & Ball milling & $65.2 \%$ & $1 \mathrm{M} \mathrm{NaClO}_{4}$ in EC:DEC (1:1) with $5 \% \mathrm{FEC}$ & $315 / 25$ th $/ 0.1 \mathrm{C}$ & $80 / 2 C$ & [56] \\
\hline $\begin{array}{l}\text { CoP@C-rGO-NF } \\
\text { (nickel foam) }\end{array}$ & $\mathrm{NaH}_{2} \mathrm{PO}_{2}$ phosphidation & $47.3 \%$ & $1 \mathrm{M} \mathrm{NaClO}$ in PC with 5\% FEC & $437.1 / 100$ th $/ 0.1 \mathrm{C}$ & $46.2 / 1.6 C$ & [18] \\
\hline $\begin{array}{l}\mathrm{Co}_{2} \mathrm{P} / \mathrm{N}, \mathrm{B}-\mathrm{Co} \text {-doped } \\
\text { carbon }\end{array}$ & High temperature annealing & $56.5 \%$ & $1 \mathrm{M} \mathrm{NaPF}{ }_{6}$ in $\mathrm{EC} / \mathrm{PC}$ & $\begin{array}{c}315 / 70 \text { th } / 0.05 \mathrm{C} \\
216.8 / 100 \mathrm{th} / 0.2 \mathrm{C}\end{array}$ & $110 / 1 C$ & [75] \\
\hline \multicolumn{7}{|l|}{ Copper phosphide } \\
\hline $\mathrm{CuP}_{2} /$ acetylene black & Ball milling & $65 \%$ & $1 \mathrm{M} \mathrm{NaClO}$ in EC:DEC (1:1) with 5\% FEC & $\approx 450 / 100$ th $/ 0.2 \mathrm{C}$ & $308 / 0.8 \mathrm{C}$ & [69] \\
\hline $\mathrm{CuP}_{2} /$ Super $\mathrm{P}$ & Ball milling & $\approx 67 \%$ & $1 \mathrm{M} \mathrm{NaClO}$ in EC:DEC (1:1) with 8\% FEC & $\approx 430 / 30$ th $/ 0.15 \mathrm{C}$ & $178 / 2 \mathrm{C}$ & [55] \\
\hline $\mathrm{Cu}_{3} \mathrm{P}$ nanowire & $\mathrm{NaH}_{2} \mathrm{PO}_{2}$ phosphidation & $80.6 \%$ & $1 \mathrm{M} \mathrm{NaClO}$ in EC:DEC (1:1) with 5\% FEC & $\begin{array}{c}\text { 249.2/50th/0.1C } \\
215.2 / 100 \text { th } / 0.2 C \\
178.8 / 100 \text { th } / 0.5 C \\
133.8 / 260 \text { th } / 1 C\end{array}$ & $\approx 120 / 5 C$ & [65] \\
\hline \multicolumn{7}{|l|}{ Iron phosphide } \\
\hline $\mathrm{FeP}_{4}$ & Ball milling & $84.1 \%$ & $1 \mathrm{M} \mathrm{NaPF}_{6}$ in EC/DEC with $2 \% \mathrm{FEC}$ & 1023/30th/0.089C & $\approx 930 / 3.6 \mathrm{C}$ & [70] \\
\hline $\mathrm{FeP}$ & Ball milling & $60.2 \%$ & $1 \mathrm{M} \mathrm{NaClO}_{4}$ in EC:DEC (1:1) & $321 / 60$ th $/ 0.05 \mathrm{C}$ & - & {$[57]$} \\
\hline FeP/graphite & Ball milling & $30.8 \%$ & $1 \mathrm{M} \mathrm{NaClO}$ in EC:DEC (1:1) & 175/70th/0.05C & $134 / 0.5 \mathrm{C}$ & [76] \\
\hline CNT@FeP@C & $\mathrm{NaH}_{2} \mathrm{PO}_{2}$ phosphidation & - & $1 \mathrm{M} \mathrm{NaClO}_{4}$ in EC:DEC $(1: 1)$ & $\begin{array}{l}415 / 100 \text { th } / 0.1 \mathrm{C} \\
295 / 500^{\text {th }} / 0.5 \mathrm{C}\end{array}$ & $268 / 1.5 C$ & [66] \\
\hline \multicolumn{7}{|l|}{ Germanium phosphide } \\
\hline $\mathrm{GeP}_{5} /$ graphite & - & $92 \%$ & $1 \mathrm{M} \mathrm{NaClO}$ in EC:DEC (1:1) & 1220/60th/0.1C & $900 / 1.5 \mathrm{C}$ & [73] \\
\hline \multicolumn{7}{|l|}{ Nickel phosphide } \\
\hline \multirow[t]{3}{*}{$\mathrm{NiP}_{3}$} & $\begin{array}{l}\text { High temperature annealing } \\
\qquad(\mathrm{HT})\end{array}$ & $89 \%(\mathrm{HT})$ & $1 \mathrm{M} \mathrm{NaClO}_{4}$ in $\mathrm{PC}$ with $5 \% \mathrm{FEC}$ & $\approx 1075 / 20$ th $/ 0.16 \mathrm{C}(\mathrm{HT})$ & - & {$[71]$} \\
\hline & Ball milling (BMR) & $85.5 \%$ (BMR) & & $\approx 990 / 20$ th/0.16C (BMR) & & \\
\hline & Ball milling (BMS) & $97 \%$ (BMS) & & $\approx 900 / 20$ th $/ 0.16 \mathrm{C}$ (BMS) & & \\
\hline
\end{tabular}

$\mathrm{Se}_{4} \mathrm{P}_{4}$

Ball milling

$70.6 \%$

$1 \mathrm{M} \mathrm{NaClO}$ in EC/PC (1:1) with 5\% FEC

$804 / 60$ th $/ 0.05 C$

$332 / 3 C$

a) The cycling data are summarized as capacity/corresponding cycle number/corresponding current density. The specific capacity was calculated based on the weight of composite. The unit of capacity is $\mathrm{mA} \mathrm{h} \mathrm{g}^{-1}$. For all the data, $1 \mathrm{C}$ equals $1000 \mathrm{~mA} \mathrm{~g}^{-1}$; b) The rate capability is summarized as capacity/corresponding current density. The specific capacity was calculated based on the weight of composite. The unit of capacity is $\mathrm{mA} \mathrm{h} \mathrm{g}^{-1}$. For all the data, $1 \mathrm{C}$ equals $1000 \mathrm{~mA} \mathrm{~g}$.

Sn-P, Ge-P, and Se-P have been reported. Other active metals should be explored to synthesize metal-active phosphides, considering that these metals can effectively accommodate $\mathrm{Na}^{+}$. ii) Apart from the electrode materials, research on other components, such as electrolyte additives and binders, should be conducted. These components also play an important role in electrode performance, but little research has been reported on them. 


\section{Acknowledgements}

F.Y. and H.G. contributed equally to this work. The authors thank Dr. T. Silver for critical reading of the manuscript.

\section{Conflict of Interest}

The authors declare no conflict of interest.

\section{Keywords}

anodes, high-energy density, metal phosphides, phosphorus, sodium-ion batteries

Received: June 12, 2017

Revised: July 12, 2017

Published online: October 24, 2017

[1] M. D. Slater, D. Kim, E. Lee, C. S. Johnson, Adv. Funct. Mater. 2013 23, 947.

[2] A. Eftekhari, Z. Jian, X. Ji, ACS Appl. Mater. Interfaces 2016, 9, 4404.

[3] M.-C. Lin, M. Gong, B. Lu, Y. Wu, D.-Y. Wang, M. Guan, M. Angell, C. Chen, J. Yang, B.-J. Hwang, H. Dai, Nature 2015, 520, 324.

[4] S. W. Kim, D. H. Seo, X. Ma, G. Ceder, K. Kang, Adv. Energy Mater. 2012, 2, 710

[5] M. Sawicki, L. L. Shaw, RSC Adv. 2015, 5, 53129.

[6] X. Xiang, K. Zhang, J. Chen, Adv. Mater. 2015, 27, 5343

[7] Y. Kim, K. H. Ha, S. M. Oh, K. T. Lee, Chem.-Eur. J. 2014, 20, 11980.

[8] J. Cui, S. Yao, J.-K. Kim, Energy Storage Mater. 2016, 7, 64.

[9] M. S. Balogun, Y. Luo, W. Qiu, P. Liu, Y. Tong, Carbon 2016, 98, 162.

[10] L. Feng, H. Xue, ChemElectroChem 2017, 4, 20.

[11] J. Sun, G. Zheng, H. W. Lee, N. Liu, H. Wang, H. Yao, W. Yang, Y. Cui, Nano Lett. 2014, 14, 4573.

[12] Y. Kim, Y. Park, A. Choi, N. S. Choi, J. Kim, J. Lee, J. H. Ryu, S. M. Oh, K. T. Lee, Adv. Mater. 2013, 25, 3045.

[13] Y. Liu, A. Zhang, C. Shen, Q. Liu, X. Cao, ACS Nano 2017, 11, 5530.

[14] J. Liu, P. Kopold, C. Wu, P. A. van Aken, J. Maier, Y. Yu, Energy Environ. Sci. 2015, 8, 3531

[15] C. Wang, T. Ding, Y. Sun, X. Zhou, Y. Liu, Q. Yang, Nanoscale 2015, 7. 19241.

[16] W. Li, S. Hu, X. Luo, Z. Li, X. Sun, M. Li, F. Liu, Y. Yu, Adv. Mater. 2017, 29, 1605820

[17] Z. Li, L. Zhang, X. Ge, C. Li, S. Dong, C. Wang, L. Yin, Nano Energy 2017, 32, 494

[18] X. Ge, Z. Li, L. Yin, Nano Energy 2017, 32, 117.

[19] Y. Zhu, Y. Wen, X. Fan, T. Gao, F. Han, C. Luo, S. C. Liou, C. Wang, ACS Nano 2015, 9, 3254.

[20] H. Gao, T. Zhou, Y. Zheng, Y. Liu, J. Chen, H. Liu, Z. Guo, Adv. Energy Mater. 2016, 6, 1601037.

[21] J. Sun, H.-W. Lee, M. Pasta, H. Yuan, G. Zheng, Y. Sun, Y. Li, Y. Cui, Nat. Nanotechnol. 2015, 10, 980

[22] J. Sun, G. Zheng, H. Lee, N. Liu, H. Wang, H. Yao, W. Yang, Y. Cui, Nano Lett. 2014, 14, 4573.

[23] P. Extance, S. R. Elliott, Philos. Mag. Part B 1981, 43, 469

[24] C.-M. Park, H.--. Sohn, Adv. Mater. 2007, 19, 2465.

[25] T. Ramireddy, M. M. Rahman, T. Xing, Y. Chen, A. M. Glushenkov, J. Mater. Chem. A 2014, 2, 4282

[26] Y. Yu, W. Li, Z. Yang, Y. Jiang, Z. Yu, L. Gu, Carbon 2014, 78, 455.

[27] M. Walter, R. Erni, M. V Kovalenko, Sci. Rep. 2015, 5, 8418.
[28] W. J. Li, S. L. Chou, J. Z. Wang, H. K. Liu, S. X. Dou, Nano Lett. 2013, 13, 5480 .

[29] W. Li, Z. Yang, M. Li, Y. Jiang, X. Wei, X. Zhong, L. Gu, Y. Yu, Nano Lett. 2016, 16, 1546.

[30] N. Yabuuchi, Y. Matsuura, T. Ishikawa, S. Kuze, J. Y. Son, Y. T. Cui, H. Oji, S. Komaba, ChemElectroChem 2014, 1, 580.

[31] L. Pei, Q. Zhao, C. Chen, J. Liang, J. Chen, ChemElectroChem 2015, 2, 1652.

[32] B. Ruan, J. Wang, D. Shi, Y. Xu, S. Chou, H. Liu, J. Wang, J. Mater. Chem. A 2015, 3, 19011

[33] J. Song, Z. Yu, M. L. Gordin, X. Li, H. Peng, D. Wang, ACS Nano 2015, 9, 11933

[34] J. Qian, X. Wu, Y. Cao, X. Ai, H. Yang, Angew. Chem. 2013, 125, 4731.

[35] J. Song, Z. Yu, M. L. Gordin, S. Hu, R. Yi, D. Tang, T. Walter, M. Regula, D. Choi, X. Li, A. Manivannan, D. Wang, Nano Lett. 2014, 14, 6329 .

[36] C. Marino, A. Debenedetti, B. Fraisse, F. Favier, L. Monconduit Electrochem. Commun. 2011, 13, 346.

[37] L. Wang, X. He, J. Li, W. Sun, J. Gao, J. Guo, C. Jiang, Angew. Chem., Int. Ed. 2012, 51, 9034

[38] C. Zhang, X. Wang, Q. Liang, X. Liu, Q. Weng, J. Liu, Y. Yang, Z. Dai, K. Ding, Y. Bando, J. Tang, D. Golberg, Nano Lett. 2016, 16, 2054.

[39] J. Zhou, X. Liu, W. Cai, Y. Zhu, J. Liang, K. Zhang, Y. Lan, Z. Jiang, G. Wang, Y. Qian, Adv. Mater. 2017, 29, 17000214.

[40] S. Liu, J. Feng, X. Bian, J. Liu, H. Xu, Y. An, Energy Environ. Sci. 2017 10, 1222.

[41] J. Sun, H. W. Lee, M. Pasta, Y. Sun, W. Liu, Y. Li, H. R. Lee, N. Liu, Y. Cui, Energy Storage Mater. 2016, 4, 130.

[42] P. G. Bruce, B. Scrosati, J.-M. Tarascon, Angew. Chem., Int. Ed. 2008, 47, 2930

[43] G.-H. Lee, M. R. Jo, K. Zhang, Y.-M. Kang, J. Mater. Chem. A 2017 $5,3683$.

[44] W. Li, S. Hu, X. Luo, Z. Li, X. Sun, M. Li, F. Liu, Y. Yu, Adv. Mater. 2017, 29, 1605820

[45] R. Hultgren, N. S. Gingrich, B. E. Warren, J. Chem. Phys. 1935, 3, 351.

[46] P. W. Bridgman, J. Am. Chem. Soc. 1914, 36, 1344

[47] M. Dahbi, N. Yabuuchi, M. Fukunishi, K. Kubota, K. Chihara, K. Tokiwa, X. F. Yu, H. Ushiyama, K. Yamashita, J. Y. Son, Y. T. Cui, H. Oji, S. Komaba, Chem. Mater. 2016, 28, 1625.

[48] E. I. Jahre, D. Phosphor, W. Gunther, D. P. Stofidrucken, H. Krebs, H. Weitz, K. Worms, J. Inorg. Chem. 1943, 280, 119

[49] H. Krebs, H. Weitz, K. H. Worms, Z. Anorg. Allg. Chem. 1955, 280, 119.

[50] Y. Maruyama, S. Suzuki, K. Kobayashi, S. Tanuma, Physica B+C 1981, 105, 99

[51] S. Lange, P. Schmidt, T. Nilges, Inorg. Chem. 2007, 46, 4028.

[52] A. Nie, Y. Cheng, S. Ning, T. Foroozan, P. Yasaei, W. Li, B. Song, Y. Yuan, L. Chen, A. Salehi-Khojin, F. Mashayek, R. ShahbazianYassar, Nano Lett. 2016, 16, 2240.

[53] Y. Kim, Y. Kim, A. Choi, S. Woo, D. Mok, N. S. Choi, Y. S. Jung J. H. Ryu, S. M. Oh, K. T. Lee, Adv. Mater. 2014, 26, 4139.

[54] Y. Lu, P. Zhou, K. Lei, Q. Zhao, Z. Tao, J. Chen, Adv. Energy Mater. 2017, 7, 1601973

[55] F. Zhao, N. Han, W. Huang, J. Li, H. Ye, F. Chen, Y. Li, J. Mater. Chem. A 2015, 3, 21754

[56] W. J. Li, Q. R. Yang, S. L. Chou, J. Z. Wang, H. K. Liu, J. Power Sources 2015, 294, 627

[57] W.-J. Li, S.-L. Chou, J.-Z. Wang, H.-K. Liu, S.-X. Dou, Chem Commun. 2015, 51, 3682.

[58] X. Fan, J. Mao, Y. Zhu, C. Luo, L. Suo, T. Gao, F. Han, S. C. Liou, C. Wang, Adv. Energy Mater. 2015, 5, 1500174.

[59] W. Li, S. L. Chou, J. Z. Wang, J. H. Kim, H. K. Liu, S. X. Dou, Adv. Mater. 2014, 26, 4037. 
[60] J. Qian, Y. Xiong, Y. Cao, X. Ai, H. Yang, Nano Lett. 2014, 14, 1865.

[61] M. Zhang, R. Hu, J. Liu, L. Ouyang, J. Liu, L. Yang, M. Zhu, Electrochem. Commun. 2017, 77, 85.

[62] X. Fan, T. Gao, C. Luo, F. Wang, J. Hu, C. Wang, Nano Energy 2017, $38,350$.

[63] P. Jiang, Q. Liu, Y. Liang, J. Tian, A. M. Asiri, X. Sun, Angew. Chem., Int. Ed. 2014, 53, 12855

[64] J. Tian, Q. Liu, N. Cheng, A. M. Asiri, X. Sun, Angew. Chem., Int. Ed. 2014, 53, 9577.

[65] M. Fan, Y. Chen, Y. Xie, T. Yang, X. Shen, N. Xu, H. Yu, C. Yan, Adv. Funct. Mater. 2016, 26, 5019.

[66] F. Han, C. Y. J. Tan, Z. Gao, ChemElectroChem 2016, 3, 1054.

[67] Q. Li, Z. Li, Z. Zhang, C. Li, J. Ma, C. Wang, X. Ge, S. Dong, L. Yin, Adv. Energy Mater. 2016, 6, 1600376.

[68] D. Lan, W. Wang, L. Shi, Y. Huang, L. Hu, Q. Li, J. Mater. Chem. A 2017, 5, 5791 .
[69] S.-O. Kim, A. Manthiram, Chem. Commun. 2016, 52, 4337.

[70] W. Zhang, M. Dahbi, S. Amagasa, Y. Yamada, S. Komaba, Electrochem. Commun. 2016, 69, 11.

[71] J. Fullenwarth, A. Darwiche, A. Soares, B. Donnadieu, L. Monconduit, J. Mater. Chem. A 2014, 2, 2050.

[72] J. Qian, Y. Xiong, Y. Cao, X. Ai, H. Yang, Nano Lett. 2014, 14, 1865.

[73] W. Li, L. Ke, Y. Wei, S. Guo, L. Gan, H. Li, T. Zhai, H. Zhou, J. Mater. Chem. A 2017, 5, 4413.

[74] S. Liu, H. Zhang, L. Xu, L. Ma, X. Chen, J. Power Sources 2016, 304, 346.

[75] Y.-M. Xing, X.-H. Zhang, D.-H. Liu, W.-H. Li, L.-N. Sun, H.-B. Geng, J.-P. Zhang, H.-Y. Guan, X.-L. Wu, ChemElectroChem 2017, 4, 1395.

[76] Q.-R. Yang, W.-J. Li, S.-L. Chou, J.-Z. Wang, H.-K. Liu, RSC Adv. 2015, 5, 80536. 